\title{
Effects of Temperature Variations on the In-Plane Stability of Steel Arch Bridges
}

\author{
Jianguo Cai ${ }^{1}$; Yixiang Xu, Ph.D. ${ }^{2}$; Jian Feng, Ph.D. ${ }^{3}$; and Jin Zhang, Ph.D. ${ }^{4}$
}

\begin{abstract}
The in-plane stability of shallow parabolic arches subjected to a central concentrated load and temperature variations was investigated in this paper. The virtual work principle method was used to establish the non-linear equilibrium and buckling equations. Analytical solutions for the non-linear in-plane symmetric snap-through and antisymmetric bifurcation buckling loads were obtained. Then the effects of temperature changes on the in-plane stability for arches with supports that stiffen under compression were studied. The results show that the influence of temperature variations on the critical loads for both buckling modes (symmetric snap-through and anti-symmetric bifurcation) is significant. The critical loads for the two buckling modes are higher than those only under external loads without thermal loading. Moreover, the critical loads increase with an increase of the thermal loadings. It can also be found that the effects of applying temperature field increase when either initial stiffness coefficient $\alpha$ or the stiffening rate $\beta$ is raised. Furthermore, the effect of thermal loading on the critical load increases with the span-rise ratio $m$ for arches with any initial stiffness coefficient $\alpha$ and the stiffening rate $\beta$.
\end{abstract}

CE Database subject headings: Bridges; Arch; Steel; Buckling; Temperature effects; Structural stability; Supports.

\footnotetext{
${ }^{1}$ Ph.D. Candidate, School of Civil Engineering, Southeast University, Nanjing 210096, China. Email: caijg_ren@hotmail.com ${ }^{2}$ Lecturer, Department of Civil Engineering, Strathclyde University, Glasgow, United Kingdom. Email: yixiang.xu@strath.ac.uk ${ }^{3}$ Professor, Key Laboratory of C \& PC Structures of Ministry of Education, School of Civil Engineering, Southeast University, Nanjing 210096, China (corresponding author). Email: seucivilfj@hotmail.com ${ }^{4}$ Associate Professor, School of Civil Engineering, Southeast University, Nanjing 210096, China. Email: zhangjin@hotmail.com
} 


\section{Introduction}

Arches have been widely used in engineering practice, such as long-span roofs and bridges. Arches resist general loading by a combination of axial compression and bending actions. Since the width of an arch bridge is large, it produces sufficient restraining actions to prevent out-of-plane buckling. The analysis of in-plane stability of a shallow arch is a classical problem in applied mechanics. The classical theory for the prediction of elastic buckling loads can be referred to two books (Timoshenko and Gere 1961, Simitses 1976).

For a shallow arch, its rise is quite small and so the pre-buckling nonlinear deformations cannot be considered as negligible. Approximate solution for the classical buckling load for sinusoidal shallow arches under uniformly distributed load was given by Timoshenko and Gere (1961). Then the closed form solutions with high precision were sought by many researchers. There are two main methods to obtain the nonlinear differential equilibrium equation, i.e., the equilibrium method and the energy method. The equilibrium method was used by Simitses (1976) to study the stability of sinusoidal shallow arches on elastic foundations. The stability of shallow arches under multiple loads was investigated by Plaut (1978). Moon et al. (2007) investigated the elastic buckling of pin-ended shallow parabolic arches. Schreyer and Masur (1966) obtained the exact buckling load for fixed shallow circular arches subjected to a uniformly distributed radial load by using the energy method. Wicks (1991) deduced the buckling equations for shallow arches of arbitrary shapes. Pi et al. (2002) and Bradford et al. (2002) used the same method as Schreyer and Masur to study the stability of shallow circular arches with pin-ended and fixed supports under a uniformly distributed radial load or a concentrated central load, and pointed out that classical buckling theory overestimated both the snap-through and bifurcation buckling loads of shallow arches. Then this method was extended to study the stability of shallow arches with different supports such as pin-ended, fixed, horizontal elastic, and rotationally elastic restraints (Bradford et al. 2007, Pi et al. 2007, 2008).

In addition to external loadings, a bridge may develop stresses due to daily and seasonal temperature changes. It is an important loading case attracting widespread research interest recently (Tindal and Yoo 2003, Barr et al. 2005, Newhouse et al. 2008, Kim and Laman 2010, Washer et al. 2010 ). Although the thermal responses of various structures that are subjected to fire loading have been investigated extensively (Wang 2002), the investigation of the effects of temperature field on the buckling of arches has been quite rarely reported in the lite- 
ratures. Timoshenko and Gere (1961) gave an approximate solution for the thermal snap-through buckling of a sinusoidal shallow pin-ended arch. Then the snap-through buckling of sinusoidal and parabolic shallow pin-ended arches was studied by Vahidi and Huang (1969). However, there is a marked difference between their solution and the one given by Timosheko and Gere. Bradford (2006) studied the nonlinear in-plane behavior of a circular arch with elastic restraints subjected to thermal loading only. It was reported that nonlinear behavior of a shallow arch is similar to that of a column with a small initial geometric imperfection under axial loading, but it cannot buckle elastically in the plane of its curvature under the uniform temperature field. The nonlinear in-plane thermo-elastic buckling of a shallow pin-ended circular arch that is only subjected to a linear temperature gradient field was discussed by Pi and Bradford (2010). Heidarpour et al. (2010) recently investigated the nonlinear thermal behavior of steel arches subjected to an arbitrary thermal profile which varies along the length of the arch as well as through the depth of the cross-section, but they did not extend this research to the stability of arches.

In all aforementioned works, the supports with constant stiffness were considered. However, the stiffness of structural supports may change as they are subjected to increasing loads. When a steel arch is welded to a base plate and connected to a concrete footing with anchor bolts, the rotational stiffness of the base connection varies with the compressive loading. The characteristic of this connection for steel columns was identified by Picard et al. in a series of experiments (Picard and Beaulieu 1985, Picard et al. 1987). The influence of such supports on the stability of compressible columns was studied by Plaut (1989) and Guran (1993). Plaut (1990) extended his study to the elastic instability of a shallow sinusoidal arch by the classic method. No study appears to have been reported which has considered the in-plane elastic buckling of a shallow parabolic arch with supports under stiffening during compression and has incorporated a nonlinear pre-buckling. Most of the previous studies are limited to circular or sinusoidal arches, but parabolic arches are commonly used in civil engineering applications due to the advantage of reaching a uniform compression under a vertically distributed load. This is because that it is common to design the arches to resist a vertically distributed load that represents traffic loads and the self-weight of the bridge deck, which are transferred to arches via hangers. Therefore, parabolic shallow arch bridges are wildly used in practice (Moon et al. 2007). The parabolic arch shown in Fig.1 is a relatively simple but very useful structural form and has been extensively used in civil engineering infrastructure. It will be the main structure studied in this paper. 
The purpose of this paper is to investigate the in-plane elastic buckling of shallow parabolic arches under an external load and temperature changes. The principle of virtual work is used to establish the nonlinear equilibrium equations and to obtain the analytical solution of the buckling loads for both the antisymmetric and symmetric buckling modes. The effect of temperature variations on the in-plane stability of steel arch bridges is discussed, and the buckling behavior of arches under both external loads and temperature changes is also investigated.

\section{Basic theories of shallow arches}

An in-plane nonlinear analysis is implemented to investigate the effect of temperature changes on the stability of a parabolic arch with elastic supports subjected to a concentrated central load and temperature changes as shown in Fig. 1. The cross-section of the arch is assumed to be symmetric with respect to the $y$-axis. Considering the shallow parabolic arch with a small initial curvature, we assume that all of the assumptions for slender beams are valid, except that the arch has an initial shape described by

$$
y=\frac{1}{2 p}\left[x^{2}-(L / 2)^{2}\right] \quad x \in[-L / 2, L / 2] \quad p=\frac{L^{2}}{8 d}
$$

where $d$ and $L$ are the rise and span of the arch, respectively.

By denoting $u(x)$ and $v(x)$ as the displacements of a generic point along the $x$ and $y$ directions, the nonlinear strain-displacement relationship for this point on the cross section can be written as (Bradford et al. 2004)

$$
\varepsilon=u^{\prime}+\frac{v^{\prime} x}{p}+\frac{1}{2}\left(v^{\prime}\right)^{2}-s v^{\prime \prime},
$$

where $s$ denotes the distance of the point from the centroidal axis as indicated by the curvilinear orthogonal coordinates ots shown in Fig. 1. The term $\frac{1}{2}^{\left(v^{\prime}\right)^{2}}$ in Eq. (2) is the source of the geometric nonlinearity (Bradford et al. 2007). The axis ot runs along the arch passing through the locus of the centroid of the arch's cross sections and the axis os is perpendicular to the centroidal axis of each cross section in the arch plane.

The strain produced by the uniform temperature field $\Delta T$ can be expressed as

$$
\varepsilon_{t}=\chi \Delta T,
$$

where $\varepsilon_{t}$ is the thermally induced strain, $\Delta T$ the temperature increment relative to its ambient value, and $\chi$ the coefficient of thermal expansion that is set to $1.2 \times 10^{-5} /{ }^{\circ} \mathrm{C}$ in this study. 
On the other hand, the total strain of the arch is described by

$$
\varepsilon=\varepsilon_{e}+\varepsilon_{t}
$$

where $\varepsilon_{e}$ denotes the mechanical elastic strain. All the strains are defined as positive in tension.

Substituting Eqs.(2) and (3) into Eq. (4), we obtain

$$
u^{\prime}+\frac{v^{\prime} x}{p}+\frac{1}{2}\left(v^{\prime}\right)^{2}-s v^{\prime \prime}=\varepsilon_{e}+\chi \Delta T \Rightarrow \varepsilon_{e}=u^{\prime}+\frac{v^{\prime} x}{p}+\frac{1}{2}\left(v^{\prime}\right)^{2}-\chi \Delta T-s v^{\prime \prime}
$$

The mechanical strain $\varepsilon_{e}$ has two components, the axial strain $\varepsilon_{m}$ and the bending strain $\varepsilon_{b}$. From Eqns. (2)-(4), we can obtain the mechanical axial strain and bending strain as

$$
\varepsilon_{m}=u^{\prime}+\frac{v^{\prime} x}{p}+\frac{1}{2}\left(v^{\prime}\right)^{2}-\chi \Delta T, \quad \varepsilon_{b}=-s v^{\prime \prime} .
$$

The differential equations of equilibrium for a parabolic shallow arch with elastic supports under a concentrated central load and thermal loadings can be derived from the principle of virtual work which requires

$$
\int_{-L / 2}^{L / 2}\left[E A\left(\delta u^{\prime}+\frac{\delta v^{\prime} x}{p}+v^{\prime} \delta v^{\prime}\right) \varepsilon_{m}+E I_{z} v^{\prime \prime} \delta v^{\prime \prime}\right] d x-Q \delta v_{0}+\sum_{i= \pm L / 2} k v_{i}{ }^{\prime} \delta v_{i}{ }^{\prime}=0
$$

to be valid for all sets of kinematically admissible virtual displacements $\delta u$ and $\delta v$, where $v_{0}$ is the central vertical displacement, $k$ the stiffness of rotational elastic springs, and $E$ the temperature-dependent elastic modulus, which is assumed to be constant over the cross section and along the longitudinal axis, since the temperature change induced by the environmental condition is smaller than $100^{\circ} \mathrm{C}$.

Integrating Eq. (6) by parts leads to the differential equilibrium equation along the horizontal direction as

$$
E A \varepsilon_{m}{ }^{\prime}=0
$$

From Eq. (7), the membrane strain $\varepsilon_{m}$ is known to be constant and can be written as

$$
\varepsilon_{m}=-\frac{N}{E A}
$$

where $N$ is the actual axial compression in the arch.

Besides the horizontal differential equilibrium equation, integrating Eq. (6) by parts also leads to the differential equilibrium equation in the vertical direction as 


$$
E I_{z} v^{i x}+\frac{N}{p}+N v^{n}=0
$$

For simplicity, the following new parameter is introduced:

$$
\mu^{2}=\frac{N}{E I_{z}}
$$

and rearranged to yield

$$
\frac{v^{i x}}{\mu^{2}}+v^{\prime \prime}=-\frac{1}{p}
$$

Integrating Eq. (6) by parts can also give the boundary conditions for the arch with rotational springs as

$$
E I_{z} v^{\prime \prime}+\left.k v^{\prime}\right|_{x=L / 2}=0 \quad \text { and } \quad E I_{z} v^{\prime \prime}-\left.k v^{\prime}\right|_{x=-L / 2}=0 \text {. }
$$

When the right-hand half of an arch is used, the interval of integration on Eq. (6) is from 0 to $L / 2$. Integrating Eq. (6) also leads to the boundary conditions

$$
\left.v^{\prime}\right|_{x=0^{+}}=0 \quad \text { and } \quad E I_{z} v^{\prime \prime \prime}-\left.\frac{Q}{2}\right|_{x=0^{+}}=0 \text {, }
$$

which represent that the slope and the shear force at the mid-surface of the arch are equal to zero.

The boundary conditions for left-hand half of an arch can be obtained in the same way as

$$
\left.v^{\prime}\right|_{x=0^{-}}=0 \text { and } E I_{z} v^{\prime \prime \prime}+\left.\frac{Q}{2}\right|_{x=0^{-}}=0 \text {. }
$$

In addition, the kinematic boundary conditions

$$
v=0 \text { at } x= \pm L / 2
$$

should also be satisfied.

Plaut $(1989,1990)$ assumed that the stiffness of structural supports will change as they are subjected to increasing loads as

$$
k=a+b \frac{N L^{2}}{E I_{z}}=a+b \mu^{2} L^{2}=a+4 b \eta^{2},
$$

where $a$ and $b$ are parameters.

Now we define the non-dimensional coefficients $\alpha$ and $\beta$ as 


$$
\alpha=\frac{a L}{E I_{z}}, \quad \text { and } \quad \beta=\frac{4 b L}{E I_{z}} .
$$

Then the stiffness of structural supports which changes with the variation $k$ is

$$
k=\frac{\left(\alpha+\beta \eta^{2}\right) E I_{z}}{L}
$$

where $\alpha$ and $\beta$ are the initial stiffness coefficient and the stiffening rate respectively.

The vertical displacement can be obtained by solving Eq. (11) with the conditions in Eqs. (12)-(15) as

$$
\begin{aligned}
v= & \frac{1}{\mu^{2} p}\left[\gamma \frac{\cos \eta-\cos (\mu x)}{\cos \eta}-\frac{1}{2}\left(\mu^{2} x^{2}-\eta^{2}\right)\right] \\
& +\frac{Q}{2 E I_{z} \mu^{3}}\left\{\psi \cos (\mu x)+\frac{\left(\alpha+\beta \eta^{2}\right)(\sec \eta-1) \gamma}{\eta\left(\alpha+\beta \eta^{2}+2\right)}-\eta-M(x)[\sin (\mu x)-\mu x]\right\},
\end{aligned}
$$

where $\eta=\mu L / 2$ is the axial force coefficient. The coefficients $\gamma$ and $\psi$ can be written as

$$
\gamma=\frac{\left(\alpha+\beta \eta^{2}\right)+2}{2+\left(\alpha+\beta \eta^{2}\right) \tan \eta / \eta}, \quad \psi=\frac{\tan \eta\left[2+\left(\alpha+\beta \eta^{2}\right) \tan (\eta / 2) / \eta\right]}{2+\left(\alpha+\beta \eta^{2}\right) \tan \eta / \eta},
$$

and $M(x)$ is defined as

$$
M(x)=\left\{\begin{array}{cc}
1, & x \geq 0 \\
-1, & x<0
\end{array}\right.
$$

The average membrane strain over the arch span can be calculated from Eq. (5) as

$$
\varepsilon_{m}=\frac{1}{L} \int_{-L / 2}^{L / 2}\left(u^{\prime}+\frac{v^{\prime} x}{p}+\frac{1}{2}\left(v^{\prime}\right)^{2}-\chi \Delta T\right) d x \text {. }
$$

Also from Eq. (8), we can obtain

$$
\varepsilon_{m}=-\frac{N}{E A}=-\frac{N}{E I_{z}} \cdot \frac{I_{z}}{A}=-\mu^{2} i_{z}^{2}
$$

where $i_{z}$ is the radius of gyration of the cross section about the major principal axis given by $i_{Z}=\sqrt{I_{z} / A}$.

Then the nonlinear equilibrium conditions for shallow arches can be established by equating Eq. (17) to Eq. (18), and substituting Eq. (16) into Eq. (17). The nonlinear equilibrium conditions for rotational restrained parabolic shallow arches can be given as

$$
A_{1} \bar{Q}^{2}+B_{1} \bar{Q}+C_{1}=0
$$

where the coefficients $A_{1}, B_{1}$ and $C_{1}$ are given by

$$
A_{1}=\frac{1}{4 \eta^{4}}\left\{\frac{\eta-\sin \eta \cos \eta}{\eta} \psi^{2}-\frac{2(1-\cos \eta)^{2}}{\eta} \psi-\frac{\sin \eta(4-\cos \eta)}{\eta}+3\right\},
$$




$$
\begin{aligned}
& B_{1}=\frac{1}{\eta^{4}}\left\{\frac{\sin \eta \cos \eta-\eta}{2 \cos \eta} \gamma \psi+\frac{(1-\cos \eta)^{2}}{2 \cos \eta} \gamma\right\}, \\
& C_{1}=\left(\frac{\eta}{\theta}\right)^{2}+D_{1}-4\left(\frac{p}{L}\right)^{2} \varepsilon_{t}=\left(\frac{\eta}{\theta}\right)^{2}+\frac{1}{4 \eta^{2}}\left\{\frac{\eta-\sin \eta \cos \eta}{\eta \cos ^{2} \eta} \gamma^{2}-\frac{2 \eta^{2}}{3}\right\}-\frac{1}{16} m^{2} \varepsilon_{t},
\end{aligned}
$$

with $m=L / d$ denoting the ratio of the arch span to the arch rise, $\theta$ denoting the geometric parameter defined by $\theta=L^{2} / 4 i_{z} p$, and $\bar{Q}$ the dimensionless load defined by

$$
\bar{Q}=\frac{Q p L}{4 E I_{z}}
$$

While the arch is fully restrained against lateral displacements and twist rotations, it may buckle in either a symmetric snap-through or an anti-symmetric bifurcation mode.

\section{Snap-through buckling}

The snap-through buckling load can be obtained by finding the maximum value of $Q$ by differentiating Eq. (19) using (Schreyer and Masur 1966)

$$
\frac{d Q}{d \eta}=0
$$

Then the relationship between the dimensionless load $\bar{Q}$ and the parameter $\eta$ during the symmetric snap-through is given by

$$
A_{2} \bar{Q}^{2}+B_{2} \bar{Q}+C_{2}=0
$$

where the coefficients $A_{2}, B_{2}$ and $C_{2}$ are given by

$$
\begin{aligned}
A_{2}= & 2 A_{1}-\frac{1}{4 \eta^{4}}\left\{\left(\sin ^{2} \eta-\frac{\eta-\sin \eta \cos \eta}{2 \eta}\right) \psi^{2}+\frac{1}{2} \cos (2 \eta)-2 \cos \eta+\frac{2(\eta-\sin \eta \cos \eta)}{\eta} \psi \psi^{*}\right. \\
& \left.-\frac{2(1-\cos \eta)^{2}}{\eta} \psi^{*}-2(1-\cos \eta) \sin \eta \psi+\frac{(1-\cos \eta)^{2}}{\eta} \psi+\frac{\sin \eta(4-\cos \eta)}{2 \eta}\right\}, \\
B_{2}= & 2 B_{1}-\frac{1}{\eta^{4}}\left\{\frac{\eta(\sin \eta \cos \eta-\eta) \sin \eta}{4 \cos ^{2} \eta} \gamma \psi-\frac{\eta \sin ^{2} \eta}{2 \cos \eta} \gamma \psi+\frac{\sin \eta \cos \eta-\eta}{2 \cos \eta}\left(\gamma^{*} \psi+\gamma \psi^{*}\right)\right. \\
& \left.+\frac{\eta(1-\cos \eta) \sin \eta}{2 \cos \eta} \gamma+\frac{\eta(1-\cos \eta)^{2} \sin \eta}{4 \cos ^{2} \eta} \gamma+\frac{(1-\cos \eta)^{2}}{2 \cos \eta} \gamma^{*}\right\}, \\
C_{2}= & D_{1}-\left(\frac{\eta}{\theta}\right)^{2}-\frac{1}{4 \eta^{2}}\left\{\gamma^{2} \tan ^{2} \eta-\frac{(\eta-\sin \eta \cos \eta)(1-2 \eta \tan \eta)}{2 \eta \cos ^{2} \eta} \gamma^{2}\right. \\
& \left.+\frac{2(\eta-\sin \eta \cos \eta)}{\eta \cos ^{2} \eta} \gamma \gamma^{*}-\frac{2}{3} \eta^{2}\right\},
\end{aligned}
$$

and the coefficients $\gamma^{*}$ and $\psi^{*}$ are 


$$
\begin{gathered}
\gamma^{*}=\frac{d \gamma}{d \mu} \frac{\mu}{2}=\frac{\beta \eta^{3}-\gamma\left[\beta \eta^{2} \tan \eta+\frac{1}{2} \eta\left(\alpha+\beta \eta^{2}\right) \sec ^{2} \eta-\frac{1}{2}\left(\alpha+\beta \eta^{2}\right) \tan \eta\right]}{2 \eta+\left(\alpha+\beta \eta^{2}\right) \tan \eta}, \\
\psi^{*}=\frac{d \psi}{d \mu} \frac{\mu}{2}=\frac{\tan \eta\left[\beta \eta^{2} \tan (\eta / 2)+\eta\left(\alpha+\beta \eta^{2}\right) \sec ^{2}(\eta / 2) / 4-\left(\alpha+\beta \eta^{2}\right) \tan (\eta / 2) / 2\right]}{2 \eta+\left(\alpha+\beta \eta^{2}\right) \tan \eta} \\
+\frac{\eta \psi}{2 \sin \eta \cos \eta}-\frac{\psi\left[\beta \eta^{2} \tan \eta+\eta\left(\alpha+\beta \eta^{2}\right) \sec ^{2} \eta / 2-\left(\alpha+\beta \eta^{2}\right) \tan \eta / 2\right]}{2 \eta+\left(\alpha+\beta \eta^{2}\right) \tan \eta} .
\end{gathered}
$$

For a given value of the geometric parameter $\theta$, a solution of the symmetric snap-through buckling load and the corresponding value of the axial force parameter $\eta$ can be obtained by solving Eqs. (19) and (21) simultaneously.

\section{Bifurcation buckling}

The arch may buckle from the pre-buckling equilibrium position $u$ and $v$ to an adjacent buckling equilibrium position $u+\Delta u$ and $v+\Delta v$. In the buckled configuration, the principle of virtual work can also be used for equilibrium, which requires

$$
\begin{aligned}
& \quad \int_{-L / 2}^{L / 2}\left\{E A\left[\delta(u+\Delta u)^{\prime}+\frac{\delta(v+\Delta v)^{\prime} x}{p}+(v+\Delta v)^{\prime} \delta(v+\Delta v)^{\prime}\right]\left(\varepsilon_{m}+\Delta \varepsilon_{m}\right)+E I_{z}(v+\Delta v)^{\prime \prime} \delta(v+\Delta v)^{\prime \prime}\right\} d x \\
& -Q \delta(v+\Delta v)_{0}+\sum_{i= \pm L / 2} k(v+\Delta v)_{i}{ }^{\prime} \delta(v+\Delta v)_{i}{ }^{\prime}=0
\end{aligned}
$$

where $\Delta \varepsilon_{m}$ is the membrane strain generated during buckling, given by

$$
\Delta \varepsilon_{m}=\Delta u^{\prime}+\frac{\Delta v^{\prime} x}{p}+v^{\prime} \Delta v^{\prime}
$$

For antisymmetric bifurcation buckling, the buckling displacement $\Delta v$ is antisymmetric whereas the pre-buckling displacement $v$ is symmetric. Therefore, the terms $\Delta v^{\prime}$ and $v^{\prime} \Delta v^{\prime}$ are antisymmetric and their integrals within the interval $[-L / 2, L / 2]$ vanish. In addition, the boundary conditions require that $\Delta u=0$ at $x= \pm L / 2$, so that the average buckling strain $\Delta \varepsilon_{m}$ is zero.

Integrating Eq. (22) by parts and considering Eqs. (8)-(11) and zero average strain $\Delta \varepsilon_{m}$ during buckling, the buckling differential equilibrium equation in the vertical direction can be obtained as

$$
\Delta v^{i v}+\mu^{2} \Delta v^{\prime \prime}=0
$$

The boundary conditions for the buckling equilibrium can also be obtained by integrating Eq. (22) by parts and considering Eqs. (12)-(15), which gives

$$
E I_{z} \Delta v^{\prime \prime}+\left.k \Delta v^{\prime}\right|_{x=L / 2}=0 \quad \text { and } \quad E I_{z} \Delta v^{\prime \prime}-\left.k \Delta v^{\prime}\right|_{x=-L / 2}=0 \text {. }
$$


The general solution of Eq. (23) can be written as

$$
\Delta v=G_{1}+G_{2} x+G_{3} \sin (\mu x)+G_{4} \cos (\mu x) .
$$

Using the boundary conditions $\Delta v=0$ at $x= \pm L / 2$ and Eq. (24) leads to four linear homogeneous algebraic equations with respect to $G_{1}-G_{4}$. For the existence of non-trivial solution for $G_{l^{-}} G_{4}$, the determinant of the coefficient matrix of the four linear algebraic equations must vanish, which yields

$$
\left[\frac{\left(\alpha+\beta \eta^{2}\right) \sin \eta}{2 \eta}+\cos \eta\right]\left\{\frac{\left(\alpha+\beta \eta^{2}\right) \sin \eta}{2}+\eta^{2}\left[\sin \eta-\frac{\left(\alpha+\beta \eta^{2}\right) \cos \eta}{2 \eta}\right]\right\}=0
$$

When the first factor of Eq. (26) is set to zero, the axial force coefficient becomes $\eta=\eta_{s}$ and the corresponding buckling shape is symmetric, which will not induce antisymmetric bifurcation buckling. When the second factor of Eq. (26) is set to vanish, the coefficient $\eta=\eta_{c}$. The antisymmetric buckling shape can be obtained as:

$$
\Delta v=G_{3}\left[\sin (\mu x)-\frac{u x \sin \eta}{\eta}\right]
$$

Then, by substituting the coefficient $\eta_{c}$ into Eq. (19), the equation for the antisymmetric critical load can be derived. Accordingly, the critical load can be obtained by solving the quadratic equation.

\section{Limits for different buckling modes}

Figure 2 shows the relationship between the dimensionless load $\bar{Q}$ and the axial force coefficient $\eta$ for arches with supports that stiffen under the compressive load $(\alpha=\beta=0.5)$, where the arches have the span-rise ratio $m=100$. From the previous section, we know that the arch buckles in an antisymmetric bifurcation mode when the axial force coefficient $\eta=\eta_{c}$. Substituting $\alpha=\beta=0.5$ into the second factor of Eq. (26), we can obtain $\eta_{c}=3.8195$. For the arch with the geometric parameter $\theta=50$, the axial force increases with the concentrated central load until the antisymmetric bifurcation buckling occurs when the axial force coefficient $\eta$ reaches 3.8195. However, for the geometric parameter $\theta=16$, the upper point of bifurcation lies on the descending curve as shown in Fig. 2, which means that symmetric buckling will occur first. For the geometric parameter $\theta=8$, the maximum axial force $\eta_{\max }<\eta_{c}$, and the arch buckles in a symmetric mode.

It should be noted that the shallow arch may not buckle and it behaves just as a beam curved in elevation when the arch has lower geometric parameter $\theta$. The buckling does not 
occur for the geometric parameter $\theta=3$, due to the fact that the maximum axial force coefficient $\eta_{\max }<\eta_{s}\left(\eta_{s}=2.1498\right.$ for $\left.\alpha=\beta=0.5\right)$.

The corresponding nonlinear buckling and post-buckling behavior of arches are shown in Fig.3 as the variations of the dimensionless load $\bar{Q}$ with the dimensionless central vertical displacement $v_{0} / d . v_{0}$ is the vertical displacement at the crown $(x=0)$ of the arch. For the bifurcation buckling mode, it can be seen from Fig. 3(d) that when the external load reaches the critical value at the bifurcation buckling point, bifurcation associated with the antisymmetric deformation of the arch occurs. After bifurcation buckling, the curve becomes a straight line with negative slope until buckling occurs at another bifurcation point as indicated by the circle shown in Fig. 3(d).

For the symmetric snap-through buckling mode, it can be seen from Fig.3(b) that the dimensionless central vertical displacement increases with the external load along the nonlinear equilibrium path until the limit point is reached. If the load is further increased, there is no adjacent equilibrium configuration and the only possible equilibrium state exists at a finite distance apart. Then the arch snaps through from the limit point to another equilibrium point. A third buckling type is that the arches buckle in the symmetric snap-through mode first and then bifurcate antisymmetrically in the unstable region, which is on the descending branch of the load-defection curve as shown in Fig.3(c). For the shallow arches with lower geometric parameters $\theta$ as shown in Fig.3(a), there is no bifurcation point or limit point on the load-defection curve. The vertical displacement just increases as the external load increases and the arch will not buckle.

The typical nonlinear behavior of a shallow parabolic arch under external loads and a uniform temperature field $\Delta \mathrm{T}=30^{\circ} \mathrm{C}$ is also shown in Fig.2 and Fig.3 (broken lines). The other geometric parameters and boundary conditions, such as the span-rise ratio $m$ and the support stiffness coefficient $\alpha$ and $\beta$, are the same as the shallow arch under external loads only. It can be seen form Fig. 2 that the limits for different buckling modes are not changed with the temperature variation. For the arch with the maximal axial force coefficient $\eta_{\max } \geq \eta_{c}$, it buckles in an antisymmetric mode when the axial force coefficient $\eta=\eta_{c}$. However, if the bifurcation buckling point lies on the descending segment of the curves for the dimensionless critical load vs. axial force coefficient, snap-through buckling will occur first. For the arch with the axial force coefficient $\eta_{s} \leq \eta_{\max }<\eta_{c}$, buckling occurs as a symmetric snap-through mode. When the maximal axial force coefficient $\eta_{\max }<\eta_{s}$, the arch may not buckle, but remains in a state just as a beam curved in elevation. 
However, the buckling mode will vary with the temperature increment for the arches with the same geometry. For the arch with the geometric parameter $\theta=16$, as shown in Fig. 2(c), the arch buckles in a symmetric mode under external loads only, but the arch buckles in an antisymmetric bifurcation mode when $\Delta \mathrm{T}=30^{\circ} \mathrm{C}$.

By comparing the solid lines and broken lines in Fig.2 and Fig.3, it can be seen that the arch under a uniform temperature field $\Delta \mathrm{T}=30^{\circ} \mathrm{C}$ has an initial axial compressive force when the external load is zero, whereas it has a zero initial compressive force when $\Delta \mathrm{T}=0^{\circ} \mathrm{C}$. Furthermore, the arch has an initial upward vertical displacement for $\Delta \mathrm{T}=30^{\circ} \mathrm{C}$ when the external load is zero, which is not observed when $\Delta \mathrm{T}=0^{\circ} \mathrm{C}$. The critical loads for the two buckling modes when $\Delta \mathrm{T}=30^{\circ} \mathrm{C}$ are higher than those under external loads only.

\section{Effects of temperature variation on critical loads}

\section{Parabolic shallow arches with pin-ended supports}

The critical loads obtained by solving Eqs. (19) and (21) simultaneously and the bifurcation buckling loads given by Eqs.(19) when the axial force coefficient $\eta=\eta_{c}$ for a group of pin-ended shallow parabolic arches are shown as the variation of dimensionless critical load with the geometric parameter $\theta$ in Fig. 4. The temperature change $\Delta \mathrm{T}=30^{\circ} \mathrm{C}$ with different span-rise ratios is considered. The dimensionless critical loads for arches under external loads only are also given in Fig. 4 for comparison. It should be noted that the critical loads for arches under external loads with the same geometric parameter $\theta$ have no correlation with the span-rise ratios $m$. It can be seen that both the snap-through and bifurcation critical loads under temperature field $\Delta \mathrm{T}=30^{\circ} \mathrm{C}$ are higher than those under external loads only. For the arches with lower geometric parameters $\theta$, symmetric snap-through buckling is the dominant mode while for the larger geometric parameters $\theta$, antisymmetric bifurcation buckling is the dominant mode. Moreover, the influence of the temperature variation increases with $\theta$. However, the effect becomes less significant when $\theta>20$.

It can also be observed form Fig. 4 that the critical load increases with the span-rise ratio $m$ for both the snap-through and bifurcation buckling modes. Furthermore, the limit of geometric parameters between bifurcation and snap-through buckling modes decreases with the increase of the span-rise ratio $m$, and the effects of applying temperature increment are very little when $m<20$. 
Figure 5 shows the effects of the thermal load on the in-plane stability of shallow arches by plotting the dimensionless critical loads against the temperature increment $\Delta \mathrm{T}$ when the geometric parameter $\theta=10$. It can be found that the dimensionless critical load ratio is linearly increasing with $\Delta T$. Furthermore, the influence of the thermal loading is more significant when the span-rise ratio becomes higher.

For the arch with $\theta=10$, given small change of the temperature, it buckles in a symmetric mode, whereas when the temperature change is large (e.g. $\Delta \mathrm{T}>=23^{\circ} \mathrm{C}$ for $m=100$ ), it buckles in an antisymmetric mode. It can be seen from Fig. 5 that the limit of the temperature variation for different buckling modes increases with the decrease of the span-rise ratio $m$.

\section{Parabolic shallow arches with load-dependent supports}

The influence of temperature changes on the in-plane stability of shallow arches with supports stiffened due to compression is shown in Fig. 6 and Fig.7 as the variations of the dimensionless critical load with respect to the initial stiffness coefficient $\alpha$ and the stiffening rate $\beta$, respectively. The stiffening rate $\beta$ is equal to 0 in Fig. 6 , and the initial stiffness coefficient $\alpha$ is equal to 0 in Fig. 7. Assuming that the span-rise ratio $m$ is 20 and the geometric parameter $\theta$ is equal to 20 , the temperature changes $\Delta \mathrm{T}$ correspond to $10^{\circ} \mathrm{C}, 30^{\circ} \mathrm{C}$, and $50^{\circ} \mathrm{C}$ in Figs.6 and 7, respectively. The dimensionless critical loads for arches under a uniform temperature field $\Delta \mathrm{T}=0^{\circ} \mathrm{C}$ are also given in Figs. 6 and 7 for comparison.

It can be seen that the critical load for arches under changing temperature with arbitrary initial stiffness coefficient $\alpha$ and the stiffening rate $\beta$ is higher than that for arches under external loads only. As expected, the critical load increases with the increase of $\alpha$ or $\beta$. However, the influence of the rotational supports on the critical load becomes less significant when $\alpha$ or $\beta$ is larger. For any temperature change shown in Fig.6 and Fig.7, the increase of the critical load is very small with the initial stiffness coefficient $\alpha>5$ and the stiffening rate $\beta>0.5$.

The effects of the temperature changes on the in-plane stability of shallow arches with varying rotational resistance against compression are shown in Fig. 8 and Fig.9 by plotting the dimensionless critical load ratio $n$ against $\Delta \mathrm{T}$, given different initial stiffness ratios and stiffening rates. Ratio $n$ is defined as the ratio of the critical load for arches under external loads and a uniform temperature field to that for arches under external loads only. The initial stiffness ratios shown in Fig. 8 correspond to the values of 1, 2, and 5 respectively, and the stiffening rates shown in Fig.9 correspond to the values of $0.1,0.2$, and 0.5 respectively. The 
geometric parameter $\theta$ is assumed to be 20 in Fig. 8 and Fig.9, and the span-rise ratio $m$ with the values of 20 and 100 are considered.

It can be seen that the critical load ratio increases with the increasing of temperature changes for different initial stiffness ratios and stiffening rates, and the critical load ratios are almost linearly proportional to $\Delta T$ shown in Fig.8 and Fig.9. It can also be found that the critical load ratio increases with either the initial stiffness coefficient $\alpha$ or the stiffening rate $\beta$ for any given temperature increment. Furthermore, the effect of temperature changes on the critical load increases with the span-rise ratio $m$ for arches with any initial stiffness coefficient $\alpha$ and the stiffening rate $\beta$.

\section{Conclusions}

The static in-plane stability of parabolic shallow arches with elastic supports subjected to a concentrated central load and temperature variations was studied in this paper. The virtual work principle was adopted to establish the nonlinear equilibrium equation and the buckling equilibrium equation for arches with the support stiffness increasing with the axial force. The critical loads for both symmetric snap-through buckling and antisymmetric bifurcation buckling were obtained.

The criteria for classification of different buckling modes have been discussed. For the arch with the maximal axial force coefficient $\eta_{\max } \geq \eta_{c}$, it will buckle in an antisymmetric bifurcation mode when the axial force coefficient $\eta_{\max }=\eta_{c}$, but if the bifurcation buckling point lies on the descending segment of the curves for the dimensionless critical load vs. axial force coefficient, snap-through buckling will occur first. For the arch with the axial force coefficient $\eta_{s} \leq \eta_{\max }<\eta_{c}$, buckling occurs as a symmetric snap-through mode. When the maximal axial force coefficient $\eta_{\max }<\eta_{s}$, the arch may not buckle, but remains in a state just as a beam curved in elevation.

It was found that applying thermal loadings will significantly affect the critical loads for both the symmetric snap-through and antisymmetric bifurcation modes, as well as on the post-buckling behavior. The critical loads for the two buckling modes are higher than those without thermal loadings. Moreover, the critical loads increase almost linearly to the temperature increment. The influence of the thermal loading increases with the geometric parameter $\theta$ of shallow arches. For a shallow arch, the buckling modes may change with the temperature 
increment. The temperature variation limit for different buckling modes increases as the span-rise ratio $m$ decreases.

It has also been found that the critical load increases with either the initial stiffness coefficient $\alpha$ or the stiffening rate $\beta$. The effects of thermal loadings increase with $\alpha$ or $\beta$. Furthermore, when temperature field is applied, the critical load increase with the span-rise ratio $m$ for arches with any initial stiffness coefficient $\alpha$ and the stiffening rate $\beta$.

Future research aims to focus on issues such as the stability of the parabolic shallow arch with initial imperfection, the elastoplastic stability and measures to enhance the critical load of parabolic shallow arches.

\section{Acknowledgments}

The work presented in this article was supported by the National Natural Science Foundation of China (Grant No. 50478075) and Scientific Research Foundation of Graduate School of Southeast University (Grant No. YBJJ0817). The first author would like to thank the China Scholarship Council for sponsoring his stay at the California Institute of Technology and Professor S. Pellegrino, Mr. X. Deng, and Mr. K. Kwok for their assistance during this period. Fruitful interactions leading to the improvement of the manuscript, which were brought by the review process, are also gratefully acknowledged.

\section{References}

Barr, P.J., Stanton, J.F., and Eberhard, M.O., (2005). "Effects of Temperature Variations on Precast, Prestressed Concrete Bridge Girders." Journal of Bridge Engineering ASCE, $10(2), 186-194$.

Bradford, M.A., Uy, B., and Pi, Y.-L., (2002). "In-plane stability of arches under a central concentrated load." Journal of Engineering Mechanics ASCE, 128(7), 710-719.

Bradford, M.A., Pi, Y.-L., and Gilbert, R.I. (2004). Nonlinear analysis of shallow pinned parabolic arch, Proceedings 17th Engineering Mechanics Conference, ASCE, Reston, VA., CD-ROM, 1-8.

Bradford, M.A., (2006). "In plane nonlinear behaviour of circular pin-ended arches with elastic restraints under thermal loading." International Journal of Structural Stability and Dynamics, 6(2), 163-177.

Bradford, M.A., Wang, T., Pi, Y.-L., and Gilbert, R. I., (2007). "In-plane stability of parabolic arches with horizontal spring supports. I: Theory." Journal of Structural Engineering 
ASCE, 133(8), 1130-1137.

Guran, A., (1993). "Influence of various types of load-dependent supports on the stability of a compressible column model.” Acta Mechanica, 97, 91-100.

Heidarpour, A., Abdullah, A.A., and Bradford M.A., (2010). "Non-linear inelastic analysis of steel arches at elevated temperatures.” Engineering Structures, 66, 512-519.

Kim, W., and Laman J.A., (2010). "Integral abutment bridge response under thermal loading.” Engineering Structures, doi:10.1016/j.engstruct.2010.01.004

Moon, J., Yoon, K.-Y., Lee, T.-H. and Lee, H.-K., (2007). "In-plane Elastic Buckling of Pin-ended Shallow Parabolic Arches.” Engineering Structures, 29, 2611-2617.

Newhouse, C.D., Roberts-Wollmann, C.L., Cousins, T.E., and Davis, R.T., (2008). "Modeling Early-Age Bridge Restraint Moments: Creep, Shrinkage, and Temperature Effects." Journal of Bridge Engineering ASCE, 13(5), 431-438.

Plaut, R.H., (1978). "Stability of shallow arches under multiple loads." Journal of Engineering Mechanics Division ASCE, 104(EM5), 1015-1026

Plaut, R.H., (1989). "Column buckling when support stiffens under compression.” Journal Applied Mechanics, 56(2), 484.

Plaut, R.H., (1990)."Buckling of shallow arches with supports that stiffen when compressed." Journal of Engineering Mechanics ASCE, 116(4), 973-976.

Pi, Y.-L., Bradford, M.A., and Uy B., (2002). 'In-plane stability of arches.” International Journal of Solids and Structures, 39(1), 105-125.

Pi Y.-L., Bradford M.A., and Tin-Loi F., (2007). "Nonlinear analysis and buckling of elastically supported circular shallow arches."International Journal of Solids and Structures, 44(7-8), 2401-2425.

Pi Y.-L., Bradford M.A., and Tin-Loi F., (2008). ”Nonlinear in-plane buckling of rotationally restrained shallow arch under a central concentrated load." International Journal of Non-Linear Mechanics, 43(1), 1-17.

Pi, Y.-L., and Bradford, M.A., (2010). "Nonlinear thermoelastic buckling of pin-ended shallow arches under temperature gradient." Journal of Engineering Mechanics ASCE, doi:10.1061/(ASCE)EM.1943-7889.0000134

Picard, A. and Beaulieu, D., (1985). "Behaviour of a simple column base connection." Cana- 
dian Journal of Civil Engineering, 12, 126-136.

Picard, A., Beaulieu, D., and Crusse, P.B., (1987). "Rotational restraint of a simple column base connection." Canadian Journal of Civil Engineering, 14, 49-57.

Schreyer, H.L., and Masur, E.F., (1966). "Buckling of shallow arches.” Journal of Engineering Mechanics Division ASCE, 92(EM4), 1-17.

Simitses, G.J., (1976). An Introduction to the Elastic Stability of Structures. Prentice-Hall, Englewood Cliffs, New Jersey.

Timoshenko, S.P. and Gere, J.M., (1961). Theory of Elastic Stability. Second Edition. McGraw-Hill Co. Inc., New York.

Tindal, T.T., and Yoo, C.H., (2003). "Thermal Effects on Skewed Steel Highway Bridges and Bearing Orientation." Journal of Bridge Engineering ASCE, 8(2), 57-65.

Vahidi, B. and Huang, N.G. (1969). "Thermal buckling of shallow bimetallic two-hinged arches." Journal of Applied Mechanics ASME, 36(4), 768-774.

Wang, Y.C. (2002). Steel and Composite Structures: Design for Fire Safety. Spon Press, London.

Washer, G., Fenwick, R., and Bolleni, N., (2010). "Effects of Solar Loading on Infrared Imaging of Subsurface Features in Concrete." Journal of Bridge Engineering ASCE, doi:10.1061/(ASCE)BE.1943-5592.0000117

Wicks, P.J., (1991), "General equations for buckling of thin shallow arches of any shape." Journal of Engineering Mechanics ASCE, 117(2), 225-240. 


\section{Figure Captions}

Figure 1 Parabolic shallow arches: geometry and loading.

Figure 2 The relation between dimensionless load and axial force parameter $\eta$
(a) $\theta=3$
(b) $\theta=8$
(c) $\theta=16$
(d) $\theta=50$

Figure 3 Buckling and postbuckling behavior of shallow arches
(a) $\theta=3$
(b) $\theta=8$
(c) $\theta=16$
(d) $\theta=50$

Figure 4 Dimensionless critical load vs arch geometric parameter $\theta$ for pin-ended arches

Figure 5 Effects of temperature changes on the critical load for pin-ended arches

Figure 6 Critical loads against initial stiffness coefficient $\alpha$

Figure 7 Critical loads against stiffening rate $\beta$

Figure 8 Critical load ratios against temperature changes with different initial stiffness rates
(a) $\mathrm{m}=20$
(b) $m=100$

Figure 9 Critical load ratios against temperature changes with different stiffening rates

(a) $m=20$ (b) $m=100$ 


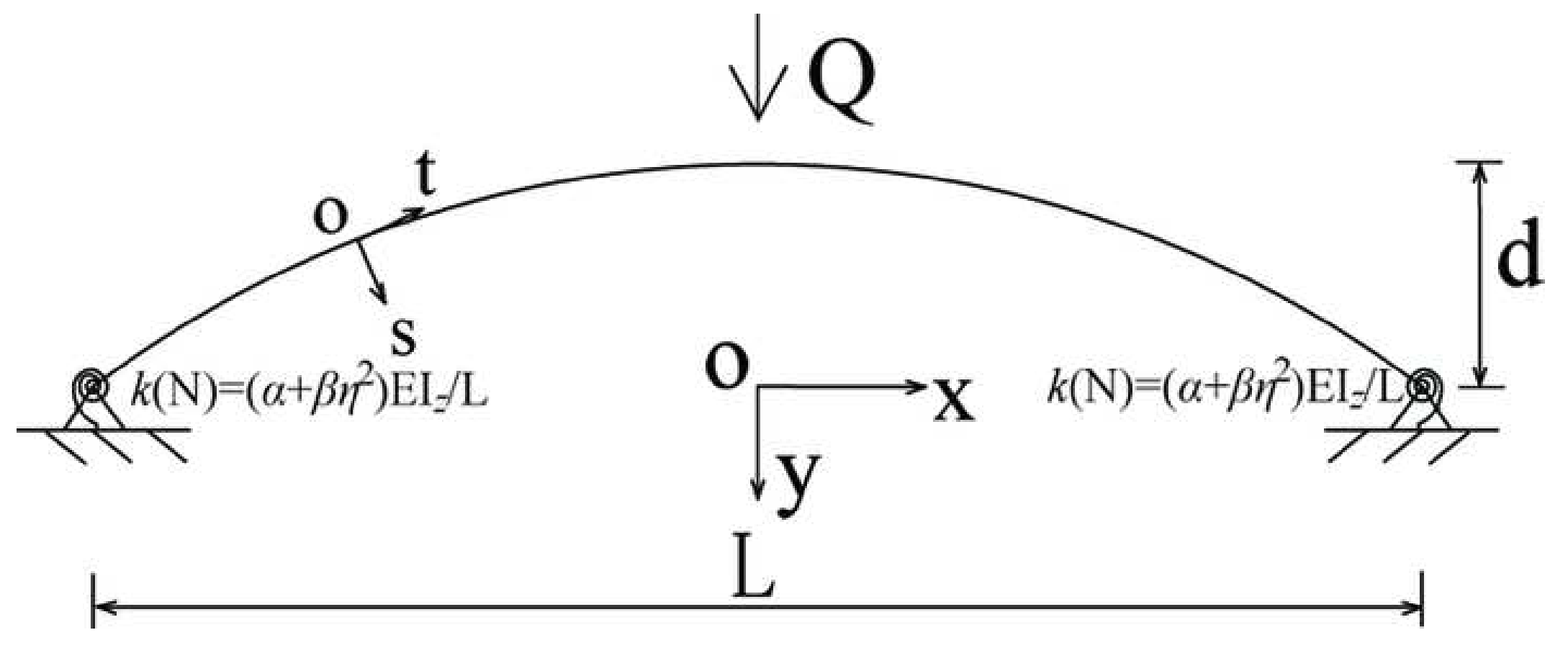

\section{Accepted Manuscript Not Copyedited}



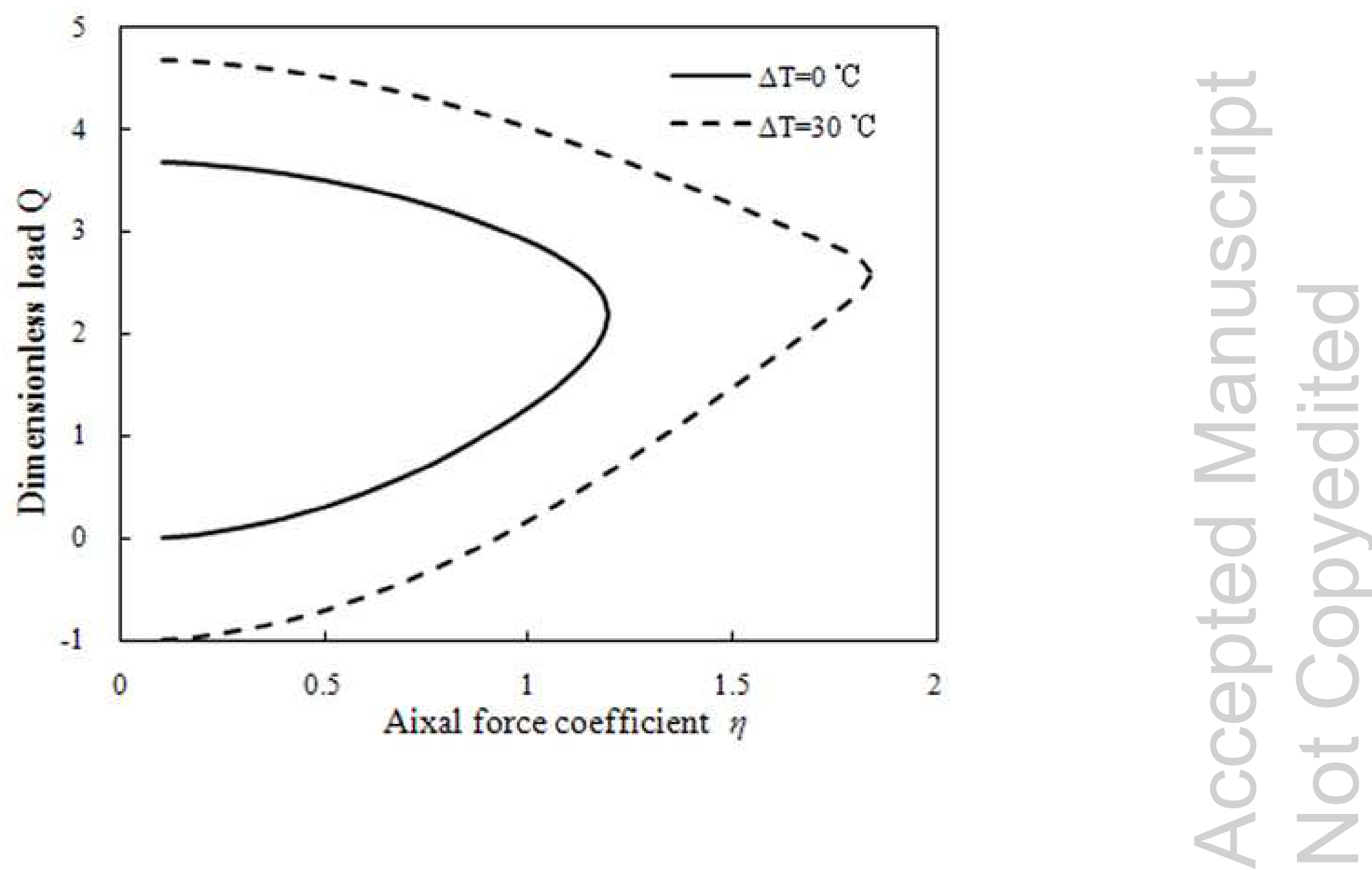

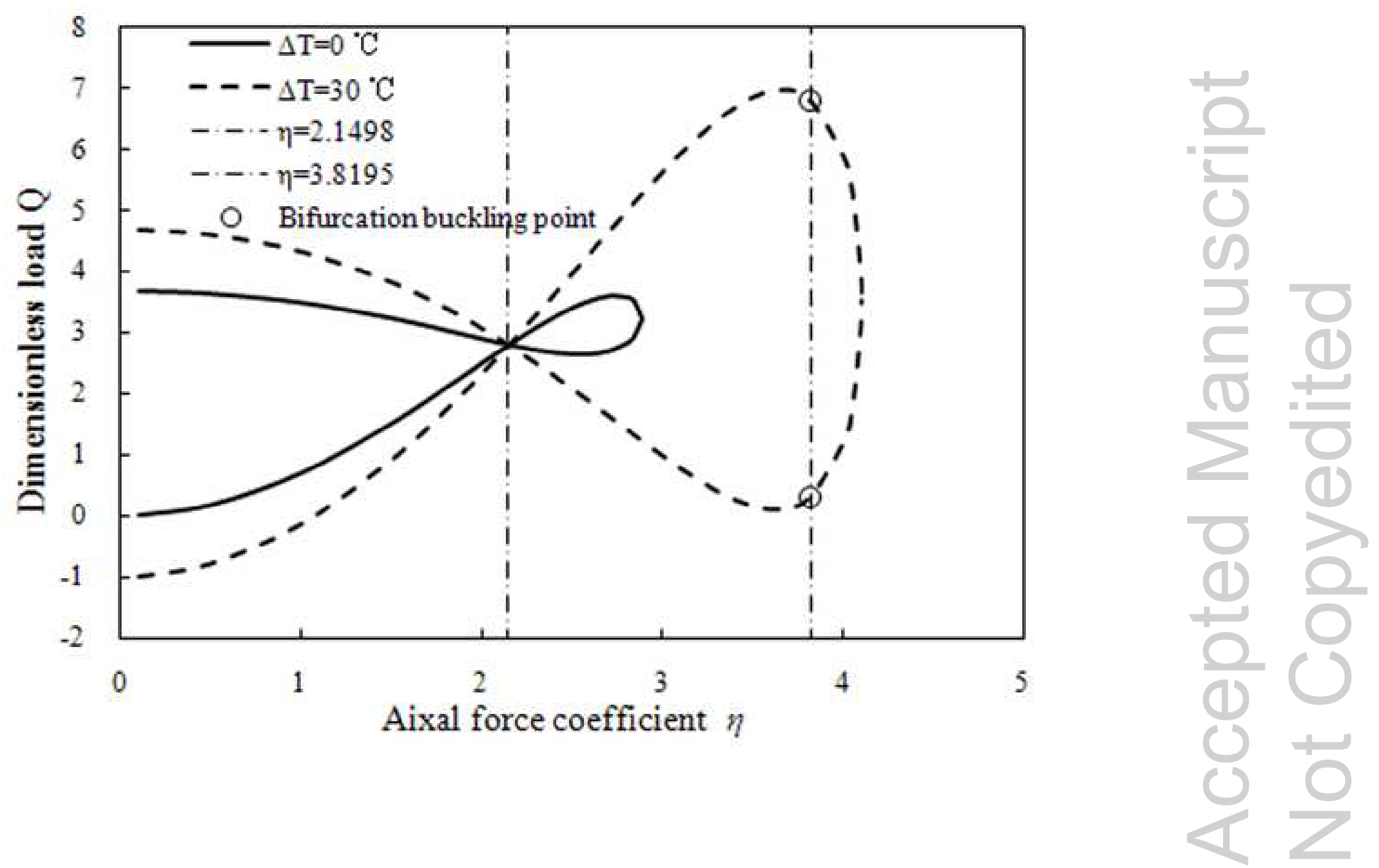

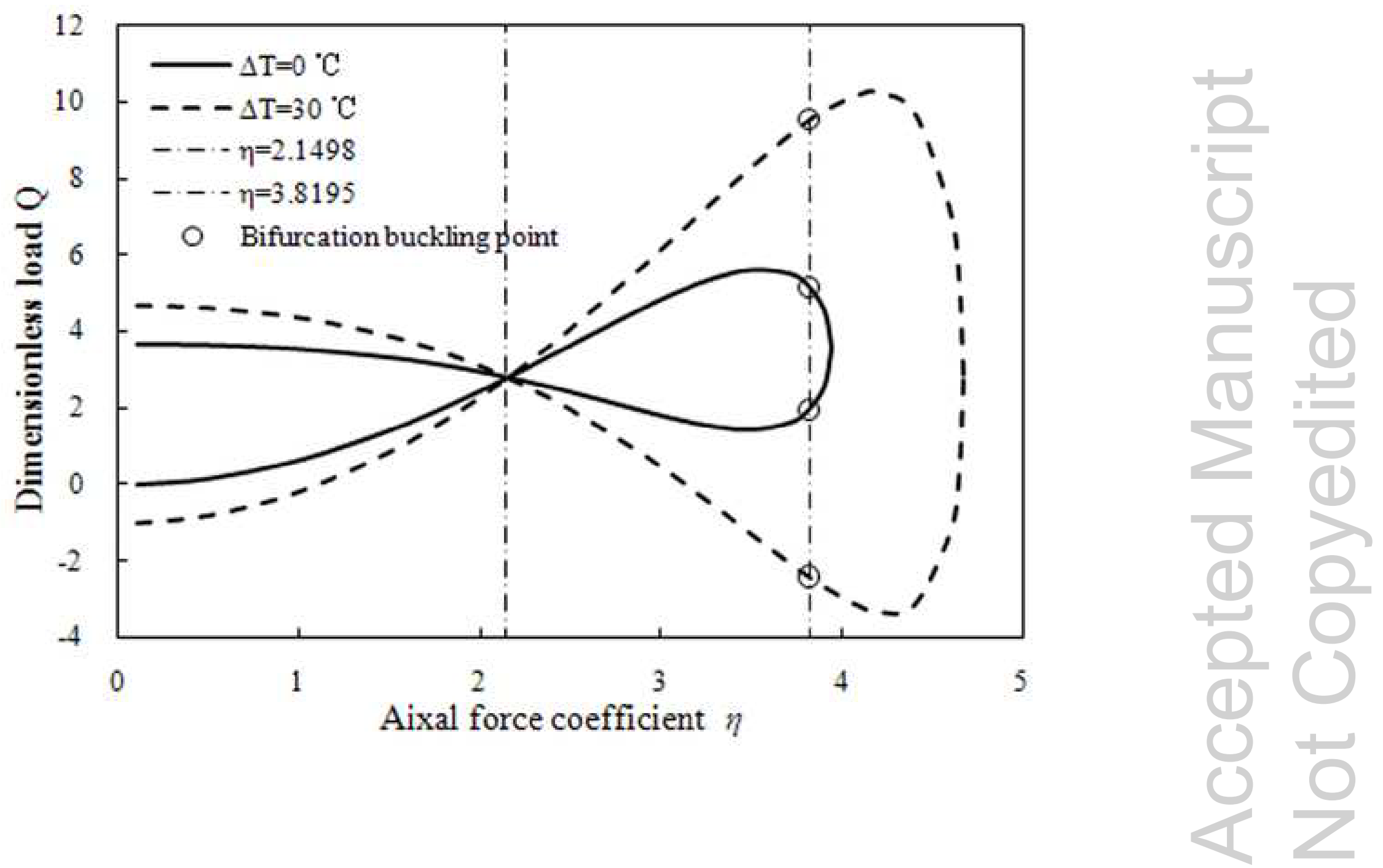

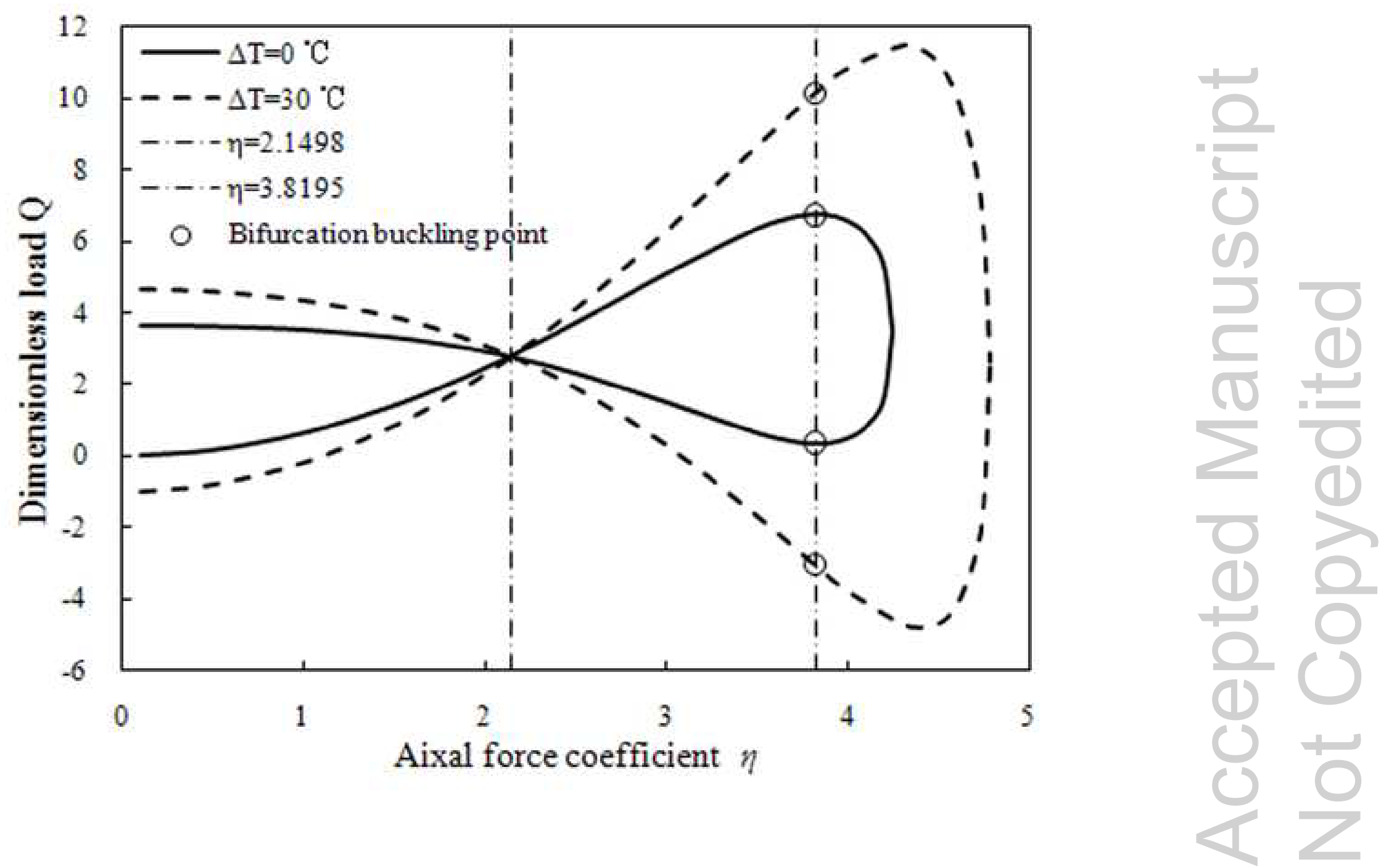

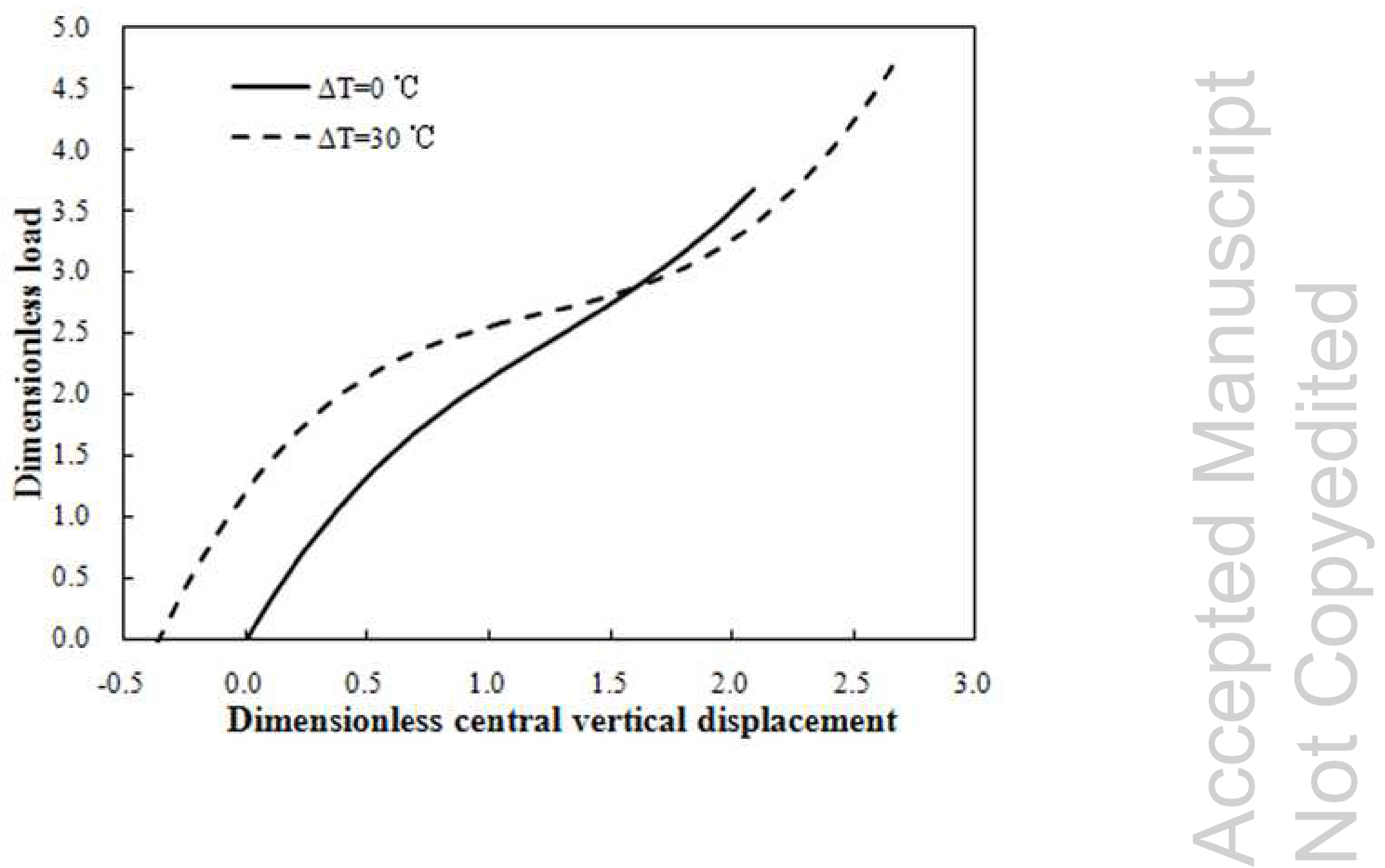

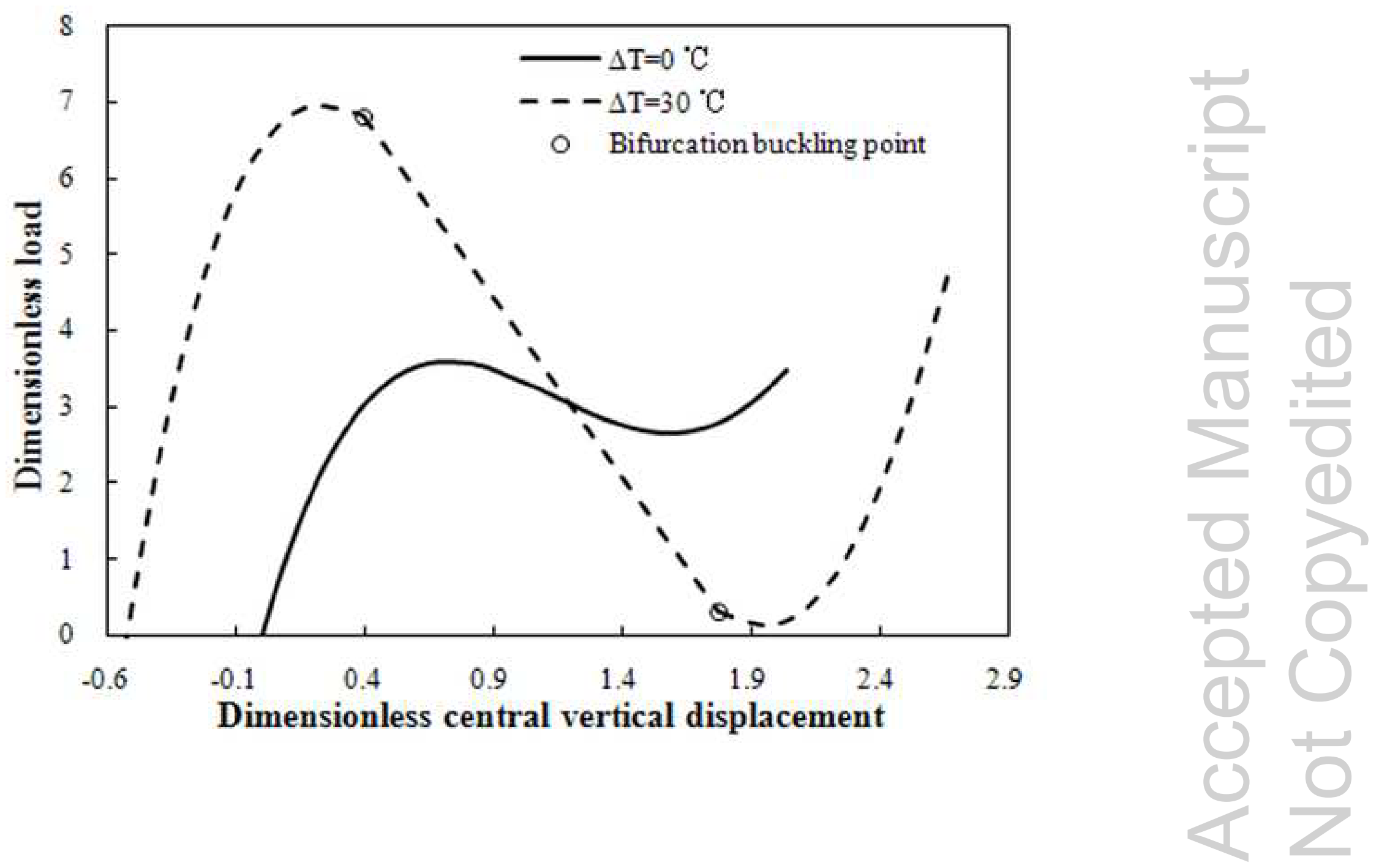

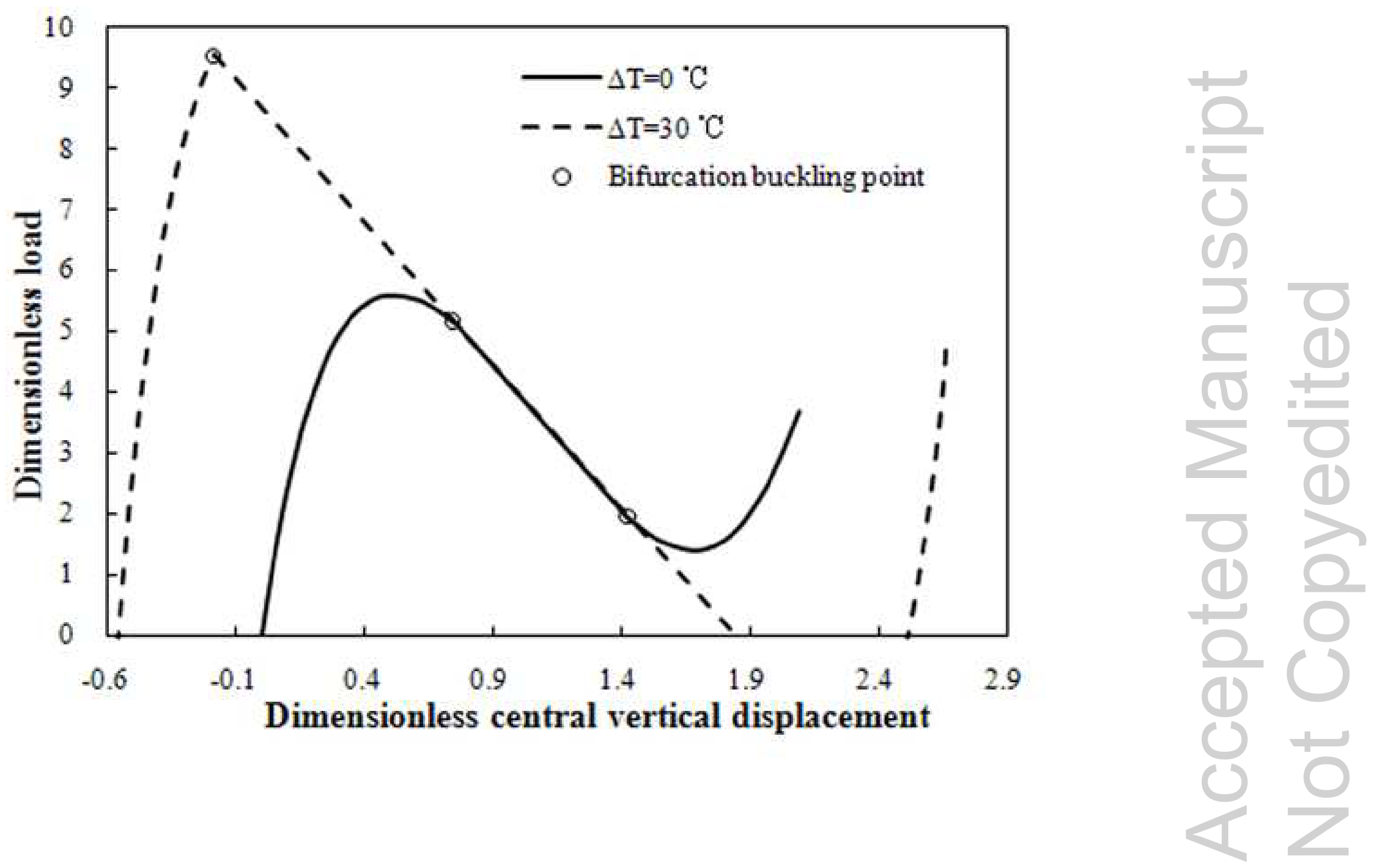

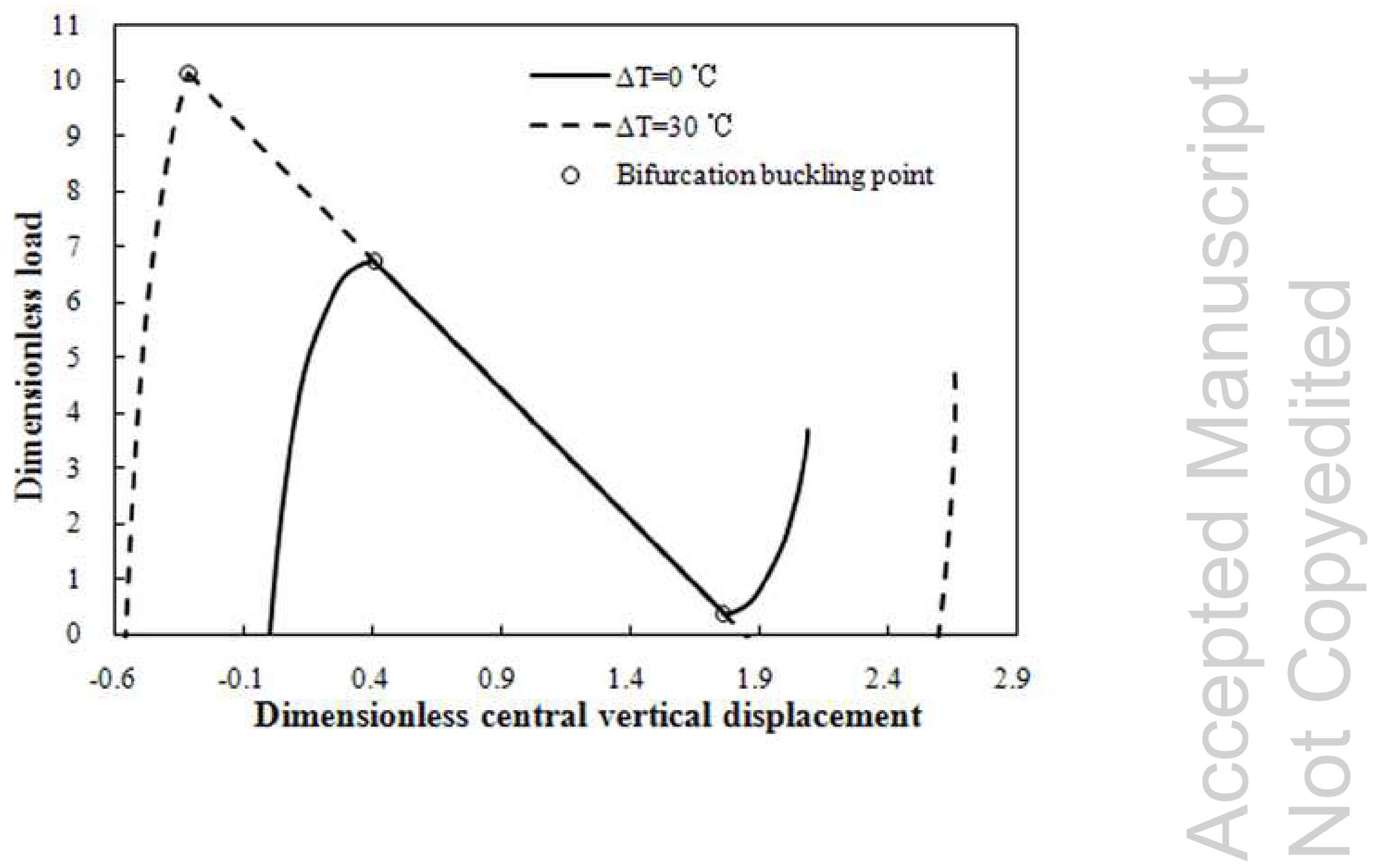

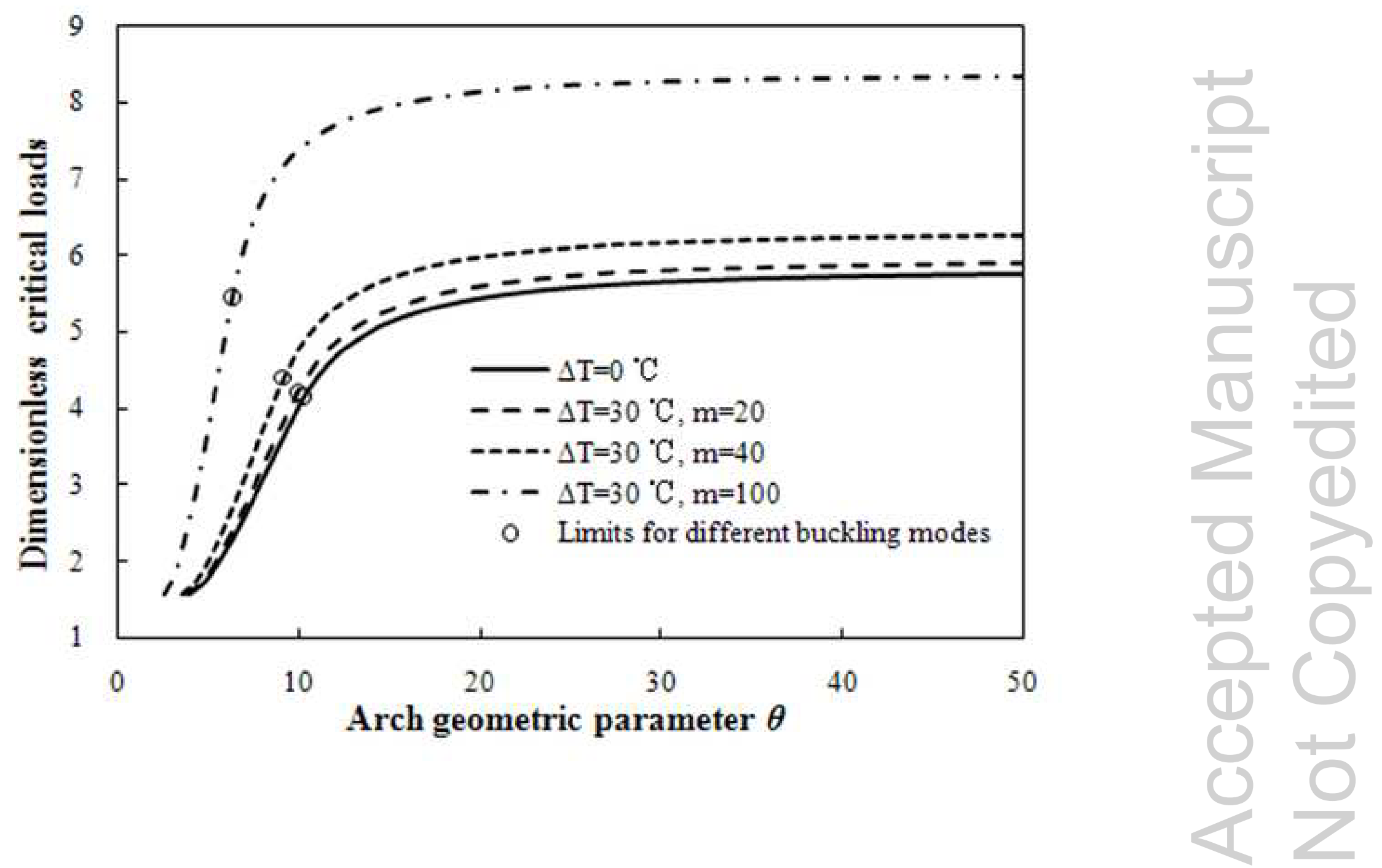

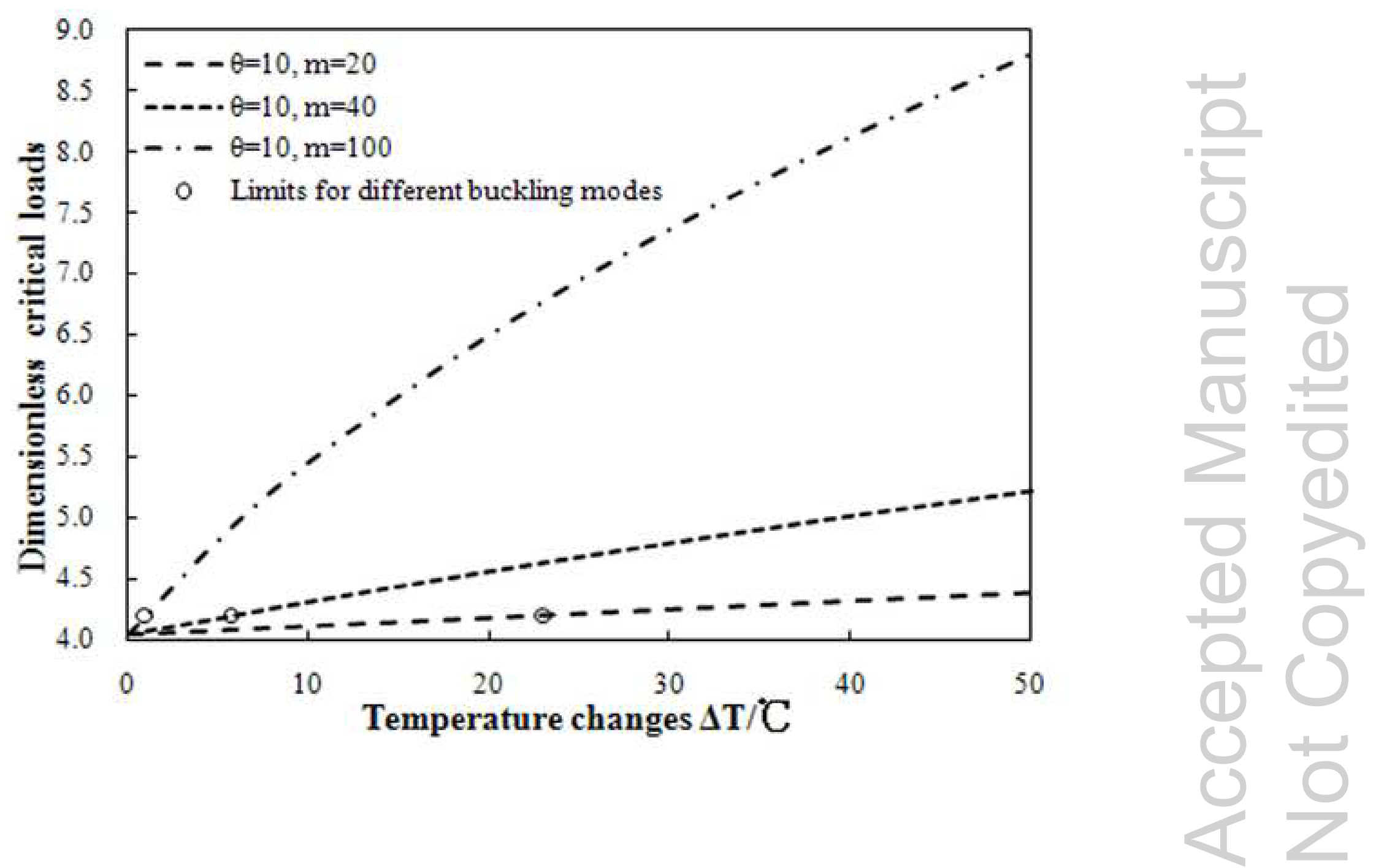

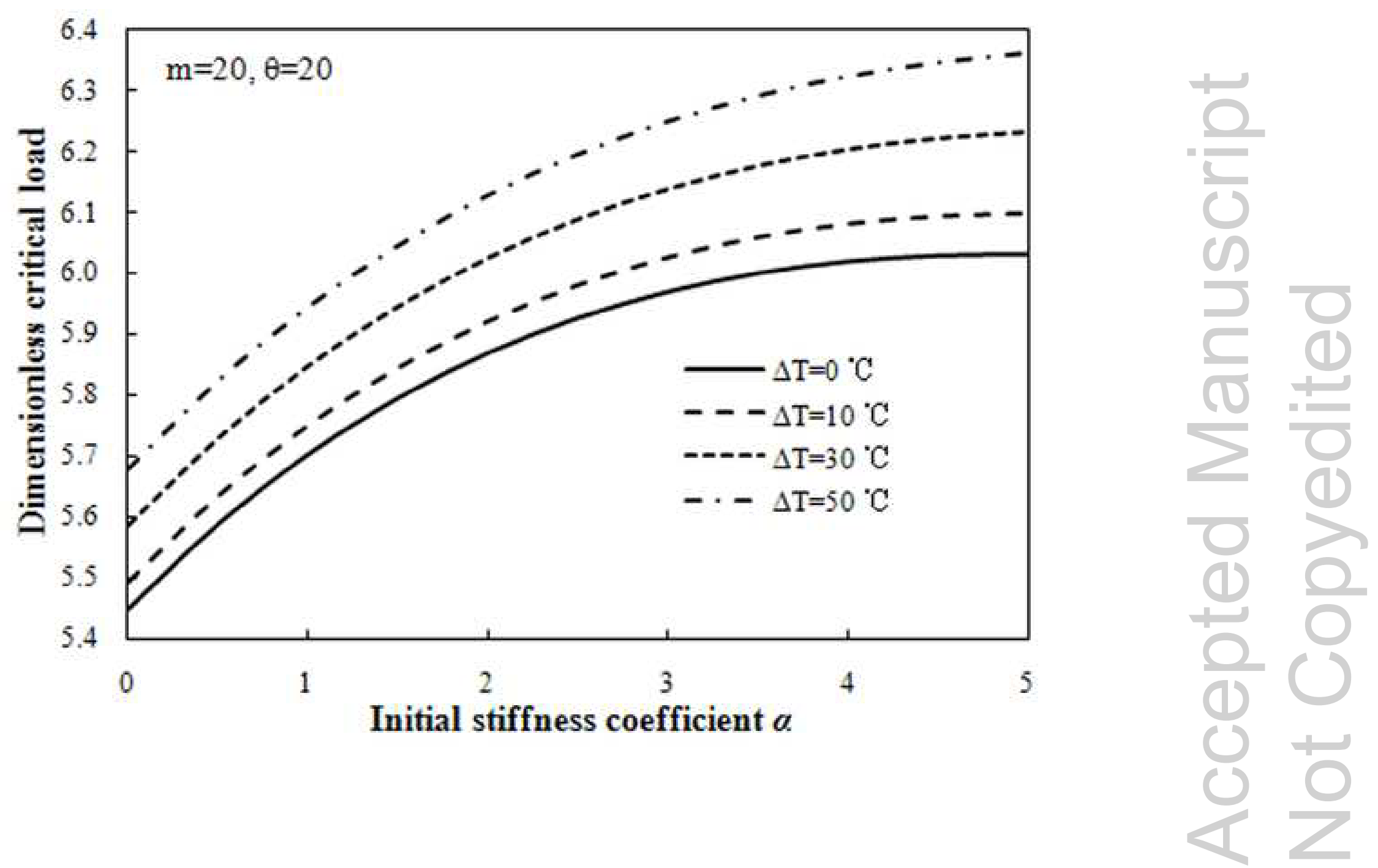

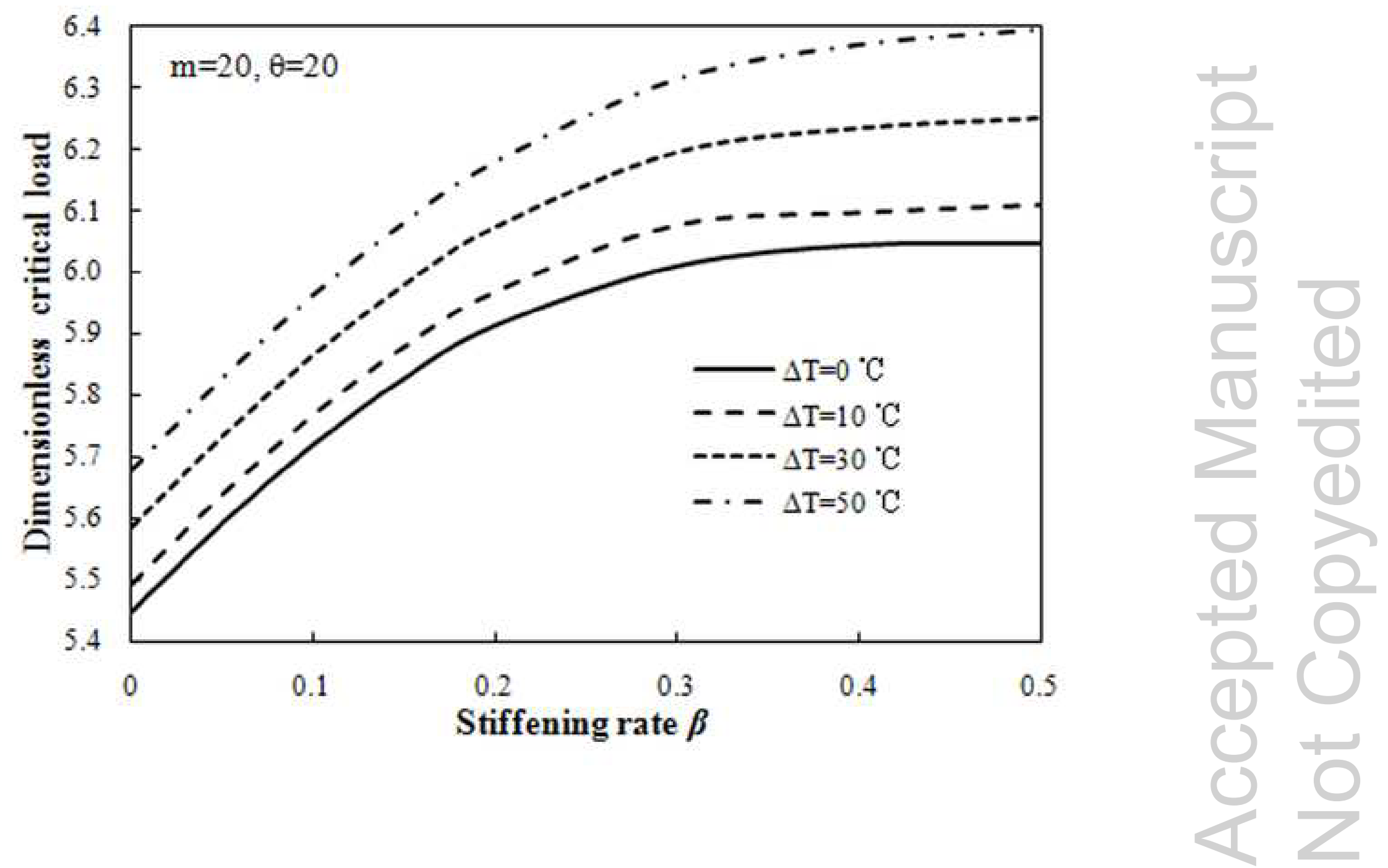

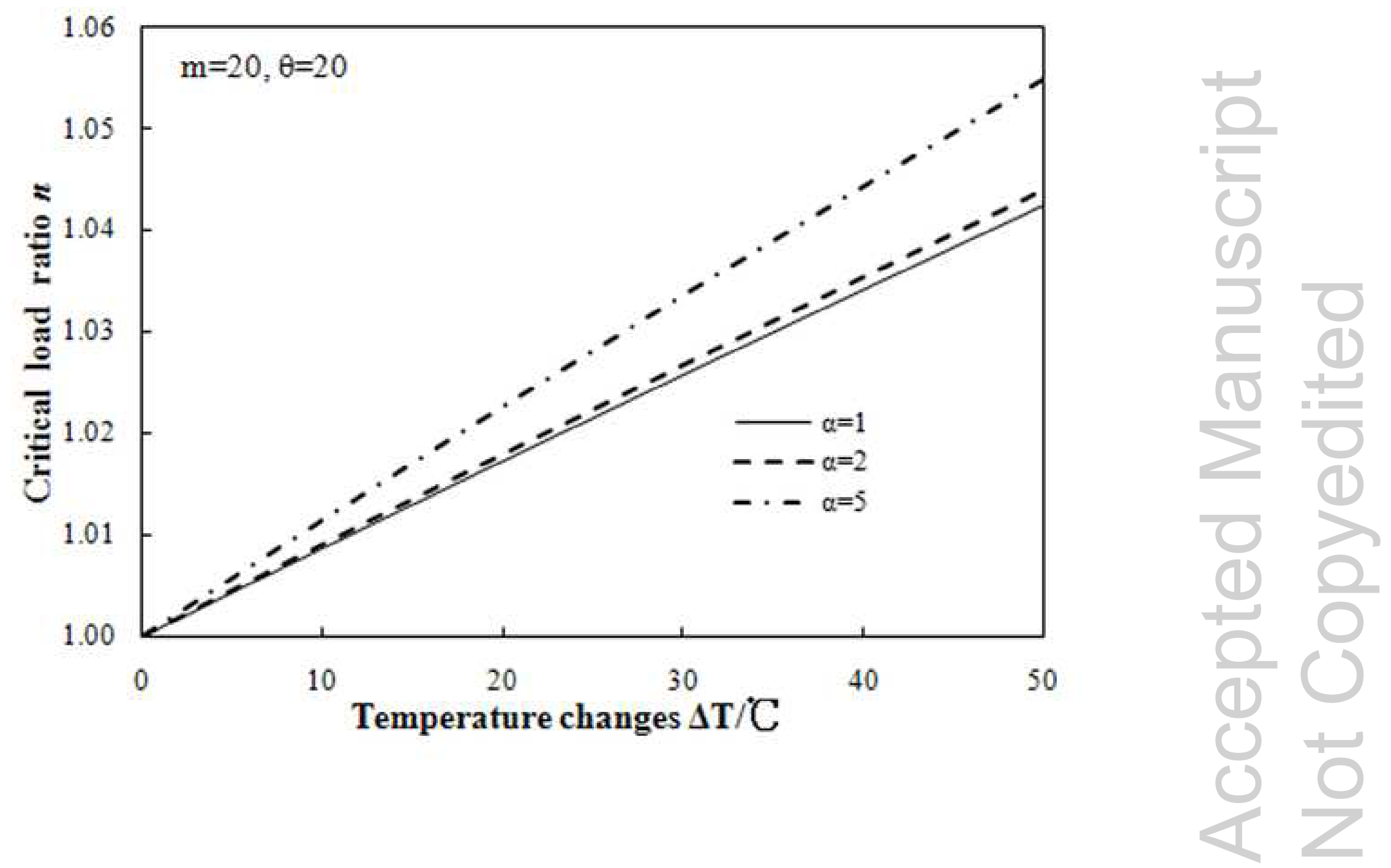

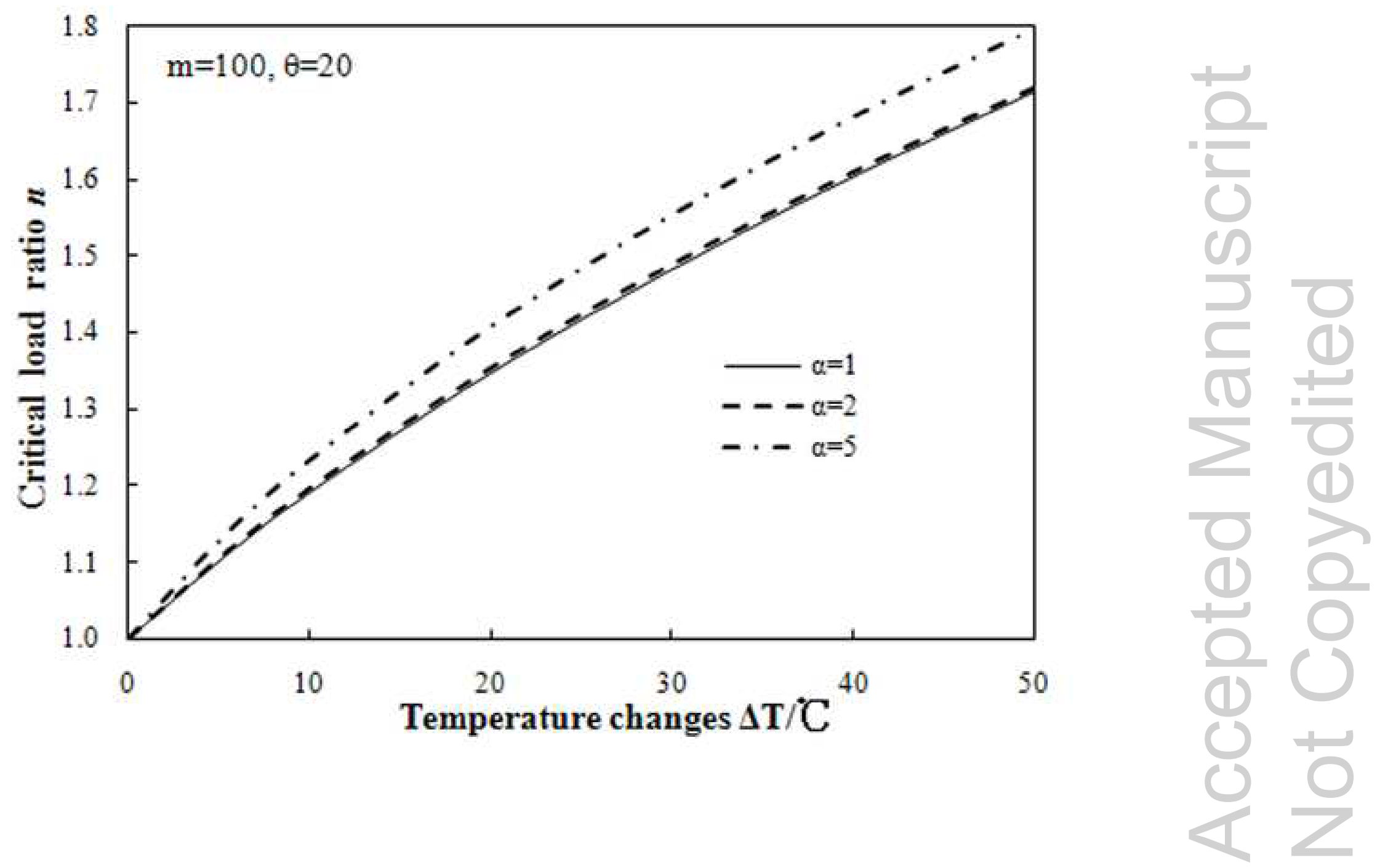


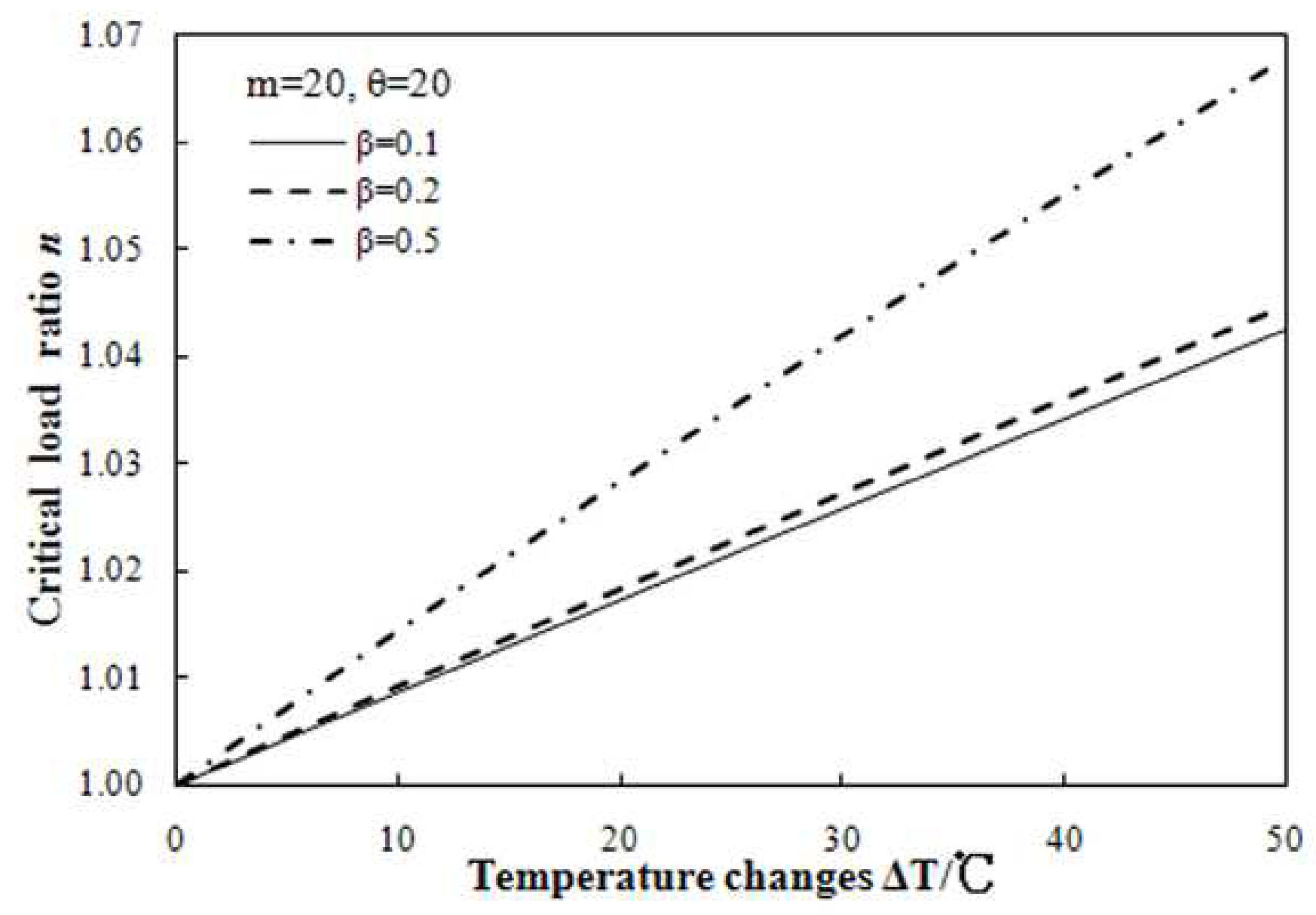



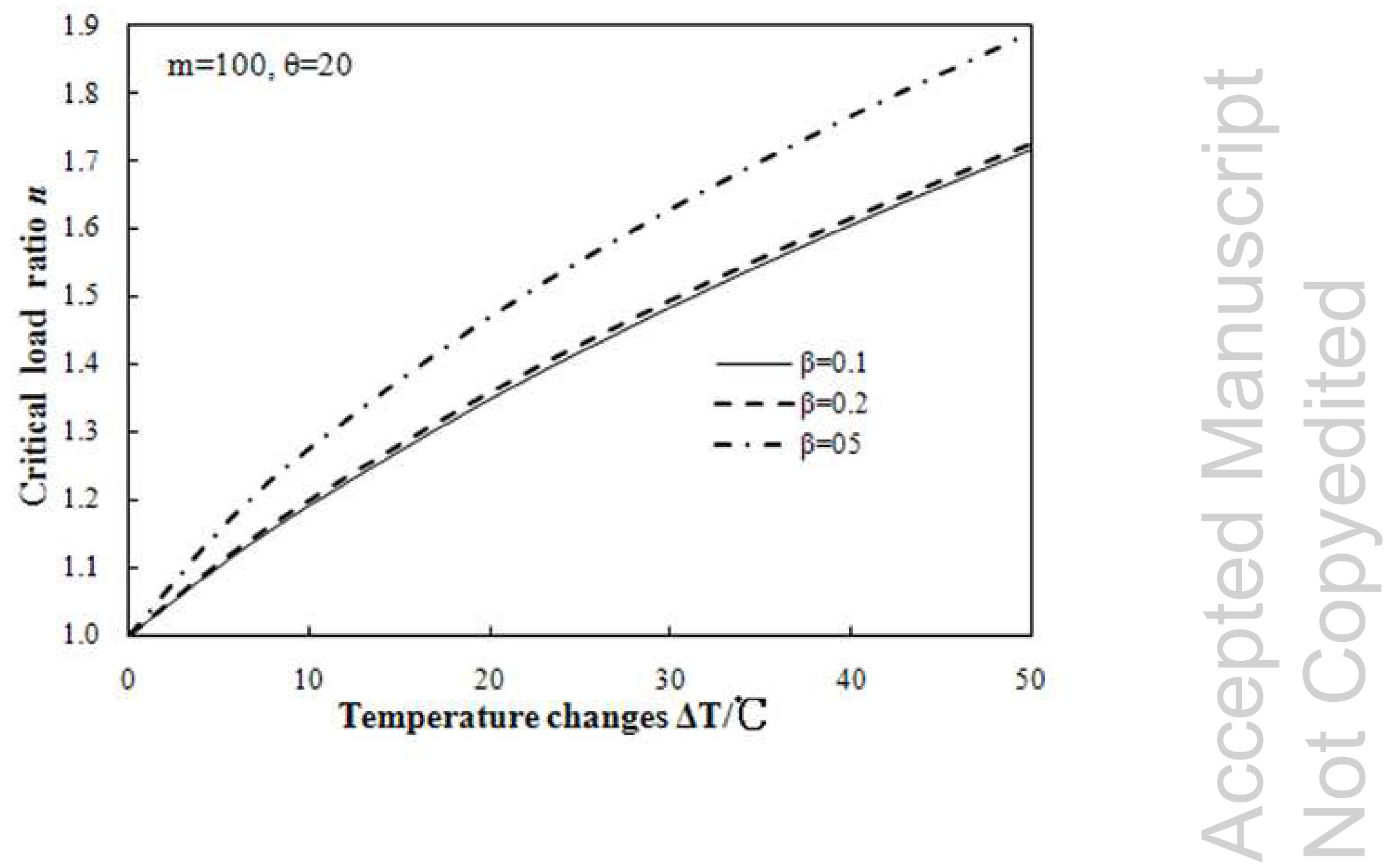